\title{
Current perspectives on the hormonal control of seed development in Arabidopsis and maize: a focus on auxin
}

\author{
Antonella Locascio ${ }^{1,2 *}{ }^{\dagger}$, Irma Roig-Villanova ${ }^{3+}$, Jamila Bernardi ${ }^{4+}$ and Serena Varotto ${ }^{1}$ \\ ${ }^{1}$ Department of Agronomy Food Natural Resources Animals Environment - University of Padova, Padova, Italy \\ 2 IBMCP-CSIC, Universidad Politécnica de Valencia, Valencia, Spain \\ ${ }^{3}$ Dipartimento di Bioscienze, Università degli Studi di Milano, Milan, Italy \\ ${ }^{4}$ Istituto di Agronomia Genetica e Coltivazioni Erbacee, Università Cattolica del Sacro Cuore, Piacenza, Italy
}

\section{Edited by:}

Lucia Colombo, University of Milan, Italy

\section{Reviewed by:}

Marcelo Carnier Dornelas,

Universidade Estadual de Campinas,

Brazil

Mario Enrico Pè, Institute of Life

Sciences ScuolaSuperiore

Sant'Anna, Italy

\section{*Correspondence}

Antonella Locascio, IBMCP-CSIC,

Universidad Politécnica de Valencia,

Avda de los Naranjos s/n, ed.8E,

46020 Valencia, Spain

e-mail:anlo3@upvnet.upv.es

${ }^{\dagger}$ These authors have contributed equally to this work.
The seed represents the unit of reproduction of flowering plants, capable of developing into another plant, and to ensure the survival of the species under unfavorable environmental conditions. It is composed of three compartments: seed coat, endosperm and embryo. Proper seed development depends on the coordination of the processes that lead to seed compartments differentiation, development and maturation. The coordination of these processes is based on the constant transmission/perception of signals by the three compartments. Phytohormones constitute one of these signals; gradients of hormones are generated in the different seed compartments, and their ratios comprise the signals that induce/inhibit particular processes in seed development. Among the hormones, auxin seems to exert a central role, as it is the only one in maintaining high levels of accumulation from fertilization to seed maturation. The gradient of auxin generated by its PIN carriers affects several processes of seed development, including pattern formation, cell division and expansion. Despite the high degree of conservation in the regulatory mechanisms that lead to seed development within the Spermatophytes, remarkable differences exist during seed maturation between Monocots and Eudicots species. For instance, in Monocots the endosperm persists until maturation, and constitutes an important compartment for nutrients storage, while in Eudicots it is reduced to a single cell layer, as the expanding embryo gradually replaces it during the maturation. This review provides an overview of the current knowledge on hormonal control of seed development, by considering the data available in two model plants: Arabidopsis thaliana, for Eudicots and Zea mays L., for Monocots. We will emphasize the control exerted by auxin on the correct progress of seed development comparing, when possible, the two species.

\section{Keywords: seed development, maize, Arabidopsis, endosperm, embryo, phytohormones, auxin}

\section{INTRODUCTION}

In order to ensure their continuation, Spermatophytes (Gymnosperm and Angiosperm plants) adapted seed development, a product of their sexual reproduction, which permits the maintenance of their lineages, allows them to be spread in the environment, and when needed, provides resistance during unfavorable environmental conditions (through the state of dormancy).

The seed comprises three compartments: embryo, endosperm and seed coat. The embryo represents the structure of the future adult plant. It encloses all the elements and fundamental patterns necessary for the new plant to develop after germination. The endosperm constitutes the reservoir for all the nutrients that the embryo will use during development and until the new plant becomes autotrophic. The seed coat derives from the integuments of the ovule and protects the vital part of the seed from mechanical injury, predators and drying out.
The seed originates from a double fertilization event, in which one sperm cell fertilizes the egg cell of the megagametophyte generating the diploid embryo, and a second sperm cell fertilizes the diploid central cell, from which derives the triploid endosperm (Reiser and Fischer, 1993; West and Harada, 1993; Goldberg et al., 1994).

Briefly, the seed development process can be divided into two main phases: (a) morphogenesis, or cellular phase, and (b) maturation (Figure 1). Morphogenesis covers all the processes including formation and structural development of the different compartments of the mature seed. In this stage the resources that provide the accessible food reserve for the embryo are also distributed and allocated. The mechanisms that lead to the definition of the structures composing the seed are highly coordinated and extremely complex. They involve a tight hormonal control and a continuous interchange of signals from and to the maternal tissues, and between the two major seed compartments, embryo and 
A
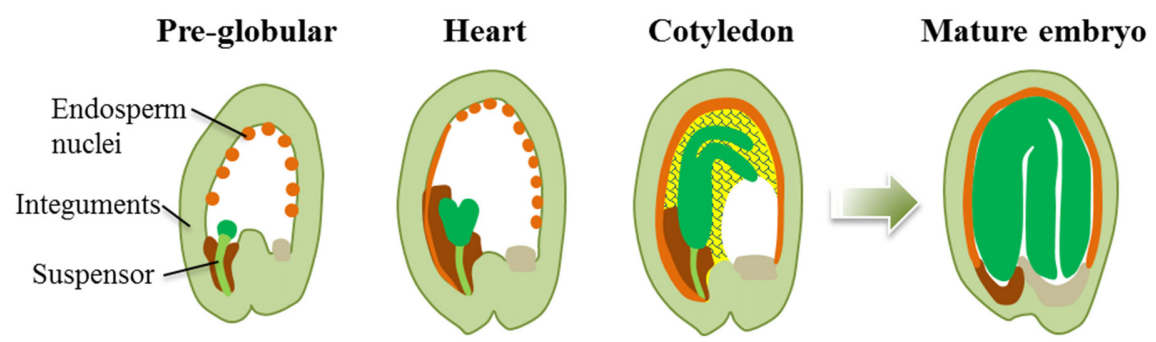

B

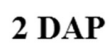

3 DAP

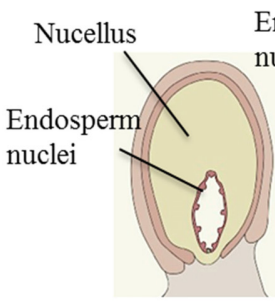

Endosperm nuclei

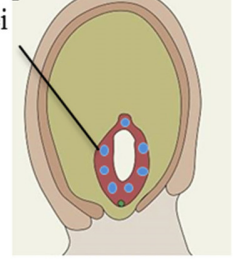

4 DAP

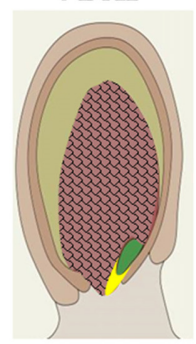

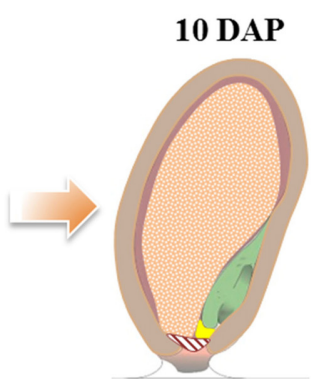

Embryo

Seed coat

- Central vacuole

(2) Cellular endosperm

- Peripheral endosperm

- Chalazal endosperm

- Micropilar endosperm

Embryo

- Pericarp

Central vacuole

(2) Cellular endosperm

- Aleurone

- Starchy endosperm

O Embryo surrounding region, ESR

Q Transfer cells, BETL

C

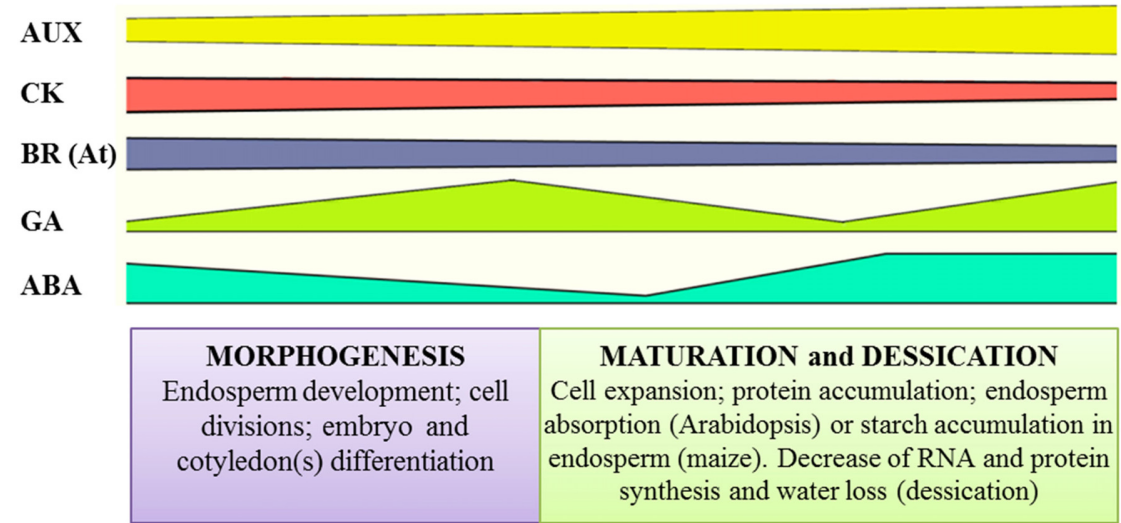

FIGURE 1 | Seed development in Arabidopsis and maize. (A) Schematic representation of seed development in Arabidopsis. Embryo development stages are indicated. The evolution of the endosperm is shown from the formation of the coenocyte, where the multiple anticlinal cell divisions generate nuclei placed all around the peripheral cytoplasm, followed by the formation of the peripheral endosperm layer. This layer evolves into the cellular endosperm after periclinal divisions and cell wall formation events. Later in the developmental program, the volume of the central vacuole progressively decreases to finally disappear, and the endosperm is absorbed almost completely and replaced by the growing embryo in the mature seed. At the end of maturation only three types of endosperm remain: the single-cell layered endosperm, the micropylar endosperm surrounding the embryo radicle, and the chalazal endosperm, adjacent to the chalazal cyst. (B) Schematic representation of seed development in maize. Stages indicate days after pollination (DAP). In parallel with Arabidopsis, the progression of seed development is showed from the definition of the coenocyte, to the cellularization of the endosperm and progressive disappearance of the central vacuole. The process of maturation, besides others modifications, ends with the expansion of the endosperm that finally occupies the largest part of the seed and the accumulation of starch in its cells that progressively undergo programmed cell death. (C) Schematic trend of hormone accumulation during seed development. The high level of auxin (AUX) present during all the seed development phases suggests that this hormone has a key role throughout the entire program of seed formation. The pattern of Cytokinins (CK) accumulation is the opposite with respect to auxin. CKs have a prominent role during the phase that involves cell divisions, decreasing progressively during the maturation phase, when cell expansion prevails. The brassinosteroids (BR) follow the same pattern of CKs. The highest concentration of BRs is shown at the beginning of seed development, and is detected in the maternally derived tissues (i.e., integuments). Their levels decrease at the end of maturation. The pattern of accumulation of Gibberellins (GA) is characteristic, showing two peaks corresponding to specific phases of seed development: the stage of embryo differentiation, when the GAs promote cell growth and expansion, and the end of the maturation phase, when they activate proteolytic enzymes that mobilize resources from the endosperm necessary for germination. Abscissic acid (ABA) shows an accumulation pattern complementary to the GAs, being the main hormone that inhibits all the processes induced by GAs. endosperm. The incessant communication among the three parts composing the seed will ensure its coordinated development.

Maturation is the physiological process that ends with the onset of the state of seed dormancy. In this stage the seed loses up to $95 \%$ of its water content (desiccation), nutrients are stored in the endosperm (Monocots) or in the cotyledons (Eudicots), cell cycle activities are stopped, RNA and protein synthesis decrease (Sheridan and Clark, 1987; Goldberg et al., 1989, 1994; Raz et al., 2001). Embryo growth during maturation is exclusively characterized by events of cellular expansion without cell divisions, and 
subsequently cell differentiation. During late maturation the seed is metabolically quiescent and highly tolerant to hydric stress (state of dormancy).

The study of plant embryogenesis and seed development has been facilitated by the characterization of mutants (Parcy and Giraudat, 1997; Gazzarrini et al., 2004; Yang et al., 2008; Pignocchi et al., 2009; Xing et al., 2013). Thanks to functional analysis of mutants and misexpression experiments some of the genes and "signals" affecting seed development have been discovered (Garcia et al., 2003; Luo et al., 2005; Ohto et al., 2005, 2009; Chourey et al., 2006; Wang et al., 2010a). In addition, QTL mappings allowed the identification of several loci with significant effect on seed weight and size (Orsi and Tanksley, 2009). Nevertheless, the molecular mechanisms that control the transition into the maturation phase and those that precede cell growth and division are not yet fully elucidated.

Many of the studies on seed development use Arabidopsis thaliana as model plant for the Eudicots and Zea mays L. for the Monocots. Despite the fact that Monocots and Eudicots share the same seed structures, the processes that lead to seed development and maturation reveal remarkable differences between the two groups.

In this review, we discuss the relevance of the communications between the three compartments of the seed during its development, by a comparative analysis of the latest findings in Arabidopsis and maize. We will summarize the elements that participate in the "flow" of signals that control seed development, and describe in more detail the regulation of this process exerted by the phytohormones, particularly by auxin.

\section{THE PROCESS OF SEED DEVELOPMENT IN ARABIDOPSIS ESTABLISHMENT OF THE SEED COMPARTMENTS}

The process of seed formation, development and maturation of Arabidopsis plants has been well described in several recent reviews (Becraft and Asuncion-Crabb, 2000; Berger, 2003; Olsen, 2004; Santos-Mendoza et al., 2008; Sun et al., 2010). Soon after fertilization, the endosperm nuclei undergo successive mitotic divisions without cell wall formation, generating the multinucleate endosperm, or coenocyte (pre-globular stage) (Figure 1A). This phase is followed by cellularization of the endosperm, and the definition of three regions: the micropylar, the peripheral and chalazal endosperm (Sorensen et al., 2002). As the embryo sac expands, the central vacuole enlarges displacing the cytoplasm of the endosperm to a peripheral position. The cellularized endosperm acts as nourishing tissue that is consumed by the embryo during maturation. The main storage products (lipids and proteins) accumulate in the profusely grown cotyledons. In mature seeds, the embryo fills the seed volume, while a single peripheral endospermic cell layer persists. It contains only a few storage products and the function of these cells is important during seed dormancy, germination and seedling nourishment (Bethke et al., 2007; Holdsworth et al., 2008).

\section{IMPORTANCE OF COMMUNICATION BETWEEN THE SEED COMPARTMENTS}

A strong interdependent relationship has been described among seed compartments (Nowack et al., 2010). A failure in the development of one of these compartments, or in the "communications" through their structures, will cause defects in the mature seed, and in some cases even abortion and embryo death. The characterization of mutants presenting phenotypes affecting seed development has helped to unravel some of the communication pathways between seed structures (Chaudhury and Berger, 2001; Berger, 2003; Berger et al., 2006; Nowack et al., 2010).

Mutations affecting endosperm formation at different stages have been described. For instance, knockout mutants such as short hypocotyl under blue1 (shb1), miniseeds3 (mini3), and haiku1 and 2 ( $i k u 1$ and 2) display a reduced seed size due to alterations in the cellularization of the endosperm. SHB1 binds to the promoters of MINI3 and IKU2, which act in the same pathway to induce their expression and trigger endosperm proliferation and seed growth (Kang and Ni, 2006). These mutants also display a limitation of cell elongation in the surrounding integuments. Thus, the effect of the endosperm on the development of the seed coat points out the relevance of the communication between these two compartments. The reduced seed size in mini3, iku1, and $i k u 2$ knockout mutants has also recently been associated with a reduced triacylglycerol content in the embryo (Fatihi et al., 2013).

Genetic evidences revealed the influence of the maternal tissues on endosperm development, exerting their control through chromatin remodeling mechanisms (Drews et al., 1998; Grossniklaus et al., 1998; Chaudhury and Berger, 2001).

Furthermore, it has been shown that endosperm development is required for proper embryo development (Berger, 2003; Berger et al., 2006). Mutations affecting endosperm development (Portereiko et al., 2006; Bemer et al., 2008), cellularization (Pignocchi et al., 2009) or breakdown (Waters et al., 2013a) affect, interrupt or even prevent embryo development and growth. A failure in endosperm cellularization or development will also affect the amount of nutrients stored in the seed, which are essential for embryo maturation. One of the nutrients that largely affects the progression of embryo development is sucrose (Ruan et al., 2010). APETALA2 (AP2), which is a floral patterning regulator, together with AtSUC5 (Baud et al., 2005) is involved in the control of sucrose ratio and seed mass. ap2 mutant displays alteration in seed size leading to a bigger seed compared to the wild type (Jofuku et al., 2005). In addition to sugars, the growth-promoting phytohormones cytokinins, brassinosteroids, and auxins are considered important signaling molecules in seed development (Sun et al., 2010). A major role for brassinosteroids and auxins in the control of seed size has been elucidated (Schruff et al., 2006; Martinez-Andujar et al., 2012; Jiang et al., 2013; Jiang and Lin, 2013). An overview of the specific role of each of these hormones in seed development will be given later in this review.

Finally, LEAFY COTYLEDON1 (LEC1), LEC2, and FUSCA3 (FUS3) are genes principally expressed in the embryo, and required to maintain cell fate. Nevertheless, it has recently been shown that, toward the phase of maturation, the expression of these genes is also detectable in the endosperm. Thus, their function is determinant for both embryo development and for initiation and maintenance of the maturation phase. Unsurprisingly, alterations in their expression cause dramatic effects on seed phenotype (Bäumlein et al., 1994; Meinke et al., 1994; Lotan et al., 1998; Gazzarrini et al., 2004). 


\section{THE PROCESS OF SEED DEVELOPMENT IN MAIZE}

Maize is widely considered the model plant for studies regarding seed development in Monocots. The program of seed development in Monocots is basically the same as that in the Eudicots; from the double fertilization event to the endosperm cellularization the processes are highly conserved (Brown et al., 1996a,b) (Figure 1). The main difference between the two models is in the later stage of endosperm development. While in Arabidopsis the endosperm is absorbed at the end of the maturation phase to provide space for the embryo to grow, in maize the endosperm persists and covers other important roles on embryo development and seed organization.

After cellularization of the coenocyte four main cell types differentiate and characterize the fully developed endosperm: the basal endosperm transfer layer (BETL) or transfer cells, the aleurone layer, the starchy endosperm and the cells of the embryosurrounding region (ESR) (Figure 1B). The transfer cell domain localizes in the basal part of the endosperm. It derives from three initial cells in the chalazal region of the endosperm coenocyte that after division assume transfer cell identity (Figure 1B). The function of the BETL is to load and distribute the nutrients coming from the maternal tissues to the endosperm. Genes expressed at the early stages of the transfer cell differentiation are of special interest to understand how these cells are specified. Many of them are involved in signal transduction and/or transcriptional regulation between maternal tissue and developing seed recently reviewed in Lopato et al. (2014). The aleurone layer delimitates the transfer cell region and constitutes the outer layer of cells of the endosperm. It represents the region of separation between the seed coat and the starchy endosperm. Aleurone cell differentiation occurs exclusively in response to surface position and does not involve specific maternal signals input (Gruis et al., 2006; Reyes et al., 2010). However, recent studies showed that some phytohormones have a prominent role in the determination of aleurone cell fate (Geisler-Lee and Gallie, 2005; Bethke et al., 2006; Forestan et al., 2010). The specification of the aleurone cells also depends on the expression of specific genes such as Crinkly4 (Cr4) (Becraft et al., 1996) and Defective in kernel1 (Dek1) (Becraft and Asuncion-Crabb, 2000; Lid et al., 2002, 2005). Interestingly, dek1 mutant specifically lacks the aleurone cell layer, but still maintains the transfer cells, supporting the idea that aleurone and transfer cells originated from different specification processes (Lid et al., 2002). A large number of mutants with defects in endosperm and embryo have been described (Neuffer and Sheridan, 1980; Sheridan and Neuffer, 1980). In the defective kernel (dek) mutants, both embryo and endosperm development are generally altered, while defective endosperm (de) mutants show alterations in endosperm development (described in Manzocchi et al., 1980; Pasini et al., 2008). A subclass of dek mutants is represented by the empty pericarp (emp) mutants (Scanlon et al., 1994), which display reduced endosperm and pericarp loss. In these mutants the defects in embryo organization seem to be the origin of the compromised endosperm, pointing out, as in Arabidopsis, the importance of communication between the seed compartments. After seed maturation, the aleurone cell layer participates in the process of seed germination by synthesizing the enzymes that hydrolyze the resources stored in the endosperm and by constituting, together with the embryo, a source of oil storage (Saoussem et al., 2009).

The starchy endosperm is the largest part of the seed in which starch and proteins accumulate serving the embryo germination. It originates from the inner cell generated in the first periclinal cell division of the endosperm, in which the external cell will generate the aleurone. $\operatorname{dek} 1$ and $c r 4$ mutants curiously maintain the starchy endosperm and replace the aleurone layer with starchy cells.

The ESR is the cavity of the endosperm where the embryo develops. It supplies the nutrients and constitutes the route of communication between the embryo and the surrounding endosperm.

The characterization of seed structures formation in maize, and the genetic dissection of the process of seed development have been mainly performed by a mutational approach. Complementary to the study of mutants, advanced techniques of molecular biology offer nowadays the possibility to investigate all those cases in which the analysis of certain mutations would not be possible. For instance, the cases in which the defects in embryo/seed structures are as severe as to cause lethality. The identification of these mutations by techniques of deep sequencing provides information about gene identity and its implication in the process that has been interrupted or disturbed by the mutation. Recently, Lu et al. (2013) and Sekhon et al. (2014) made important contributions to the study of maize seed development. In their works they analyzed gene transcription by RNA-sequencing and obtained detailed information about differential gene expression between embryo and endosperm. Transcripts were classified, organized in subgroups and several interesting regulatory networks between the two compartments were proposed.

\section{HORMONAL COORDINATION OF SEED DEVELOPMENT}

Developing seeds consist of multiple tissues and cells with specific patterns of proliferation and differentiation. In order to integrate and organize cell distribution within the tissue/organ, determine cell fate, and control the progression through development, a precise spatial and temporal coordination is required. Cells are able to control all these activities through the production and perception of "signals." The transmission and perception of these signals is important not only among seed structures, but also within the same compartment to control the progression of the developmental process. Hormones constitute part of these signals (Figure 1C).

In the next sections, we summarize the current knowledge about the mechanisms of communication between the three structures of the seed, especially through the hormonal route. We cover the process of seed development from fertilization of the ovule to maturity. While other scientists have reviewed several mechanisms governing the signaling between the three seed compartments (Nowack et al., 2010), in this review we will focus on the hormonal control of seed development, especially emphasizing the role of auxin.

\section{THE ROLE OF AUXIN IN ARABIDOPSIS AND MAIZE DEVELOPMENT}

Auxin is a key hormone for plant growth and development, accomplishing important roles during the entire lifespan of the 
plant (Tanaka et al., 2006; Teale et al., 2006; Vanneste and Friml, 2009). It has been shown to be fundamental in the first steps of seed development, as well as for the determination of embryo structure and size (Hamann et al., 2002; Friml et al., 2003; Jenik and Barton, 2005; Cheng et al., 2007; Wabnik et al., 2013). In Arabidopsis it has been demonstrated that auxin plays a role in seed dormancy and germination through its crosstalk with other hormones such as Abscissic acid (ABA) (Liu et al., 2007a, 2013).

In Arabidopsis and maize correct seed development requires a coordinated crosstalk between the seed tissues (mainly embryo and endosperm). One of the most important signaling molecules involved in this communication is auxin. Auxin accumulation and distribution varies during seed development. In fact, the use of auxin marker tools revealed that, at the beginning of development, in immature Arabidopsis seeds, auxin accumulates in the embryos, concretely at the root apex, ends of cotyledon primordia and at the hypophysis (Ni et al., 2001). In maize, auxin concentration increases at the onset of endoreduplication and remains high throughout the development (Lur and Setter, 1993b). More specifically, it has been shown that auxin is low during the initial phase of endosperm development and increases from 9 to 11 days after pollination (DAP) remaining high until maturation (Lur and Setter, 1993a,b). In a recent work by Bernardi et al. (2012) it was shown that free indole-3-acetic acid (IAA) levels increase between 8 and 28 DAP with a drop at 20 DAP. These results suggest a role for auxin in all the stages of maize seed development. Auxin is involved in positional signaling during aleurone development and specification (Forestan et al., 2010). Complete loss of endogenous auxin in the embryo might be lethal, confirming a key role of this phytohormone in embryo development and germination.

The mechanism of action of auxin involves three checkpoints: biosynthesis, polar transport, and perception/transduction of the signal. These three main processes, which will be extensively discussed in the next sections, are involved in both maize (Forestan and Varotto, 2012) and Arabidopsis seed development, influencing the final size.

\section{IAA biosynthesis}

The first natural auxin identified was the IAA, which originates from its precursor, the amino acid tryptophan (Trp). Five IAA biosynthetic pathways have been proposed: four interconnected Trp-dependent IAA biosynthetic pathways, and a Trp-independent pathway (Tivendale et al., 2014). Recently, it has been discovered that YUC (flavin-monoxygenases) and TAA/TAR (tryptophan amino-transferases), two of the most relevant enzymes involved in the biosynthesis of auxin, act in the same pathway, the so-called indolic 3-pyruvic acid (IPA) pathway (Mashiguchi et al., 2011; Stepanova et al., 2011; Won et al., 2011). Based on these studies, it was proposed that YUCCA (YUC) proteins catalyze the rate-limiting step of the IPA pathway. Counts of 11 YUC genes have been made in the Arabidopsis genome (Zhao et al., 2001; Cheng et al., 2006); four of them, YUC1, YUC4, YUC10, and YUC11, being expressed in an overlapping way in the embryo (Cheng et al., 2007). While the double mutant yucl yuc4 does not show any obvious phenotype during embryogenesis, the quadruple mutant yuc1 yuc4 yuc10 yuc11 displays several morphological defects, already at the embryonic globular stage, failing also in developing hypocotyls and primary roots. This strong phenotype is similar to that displayed by the mutants in auxin signaling (monopteros, mp; bodenloss, $b d l$ ), perception (transport inhibitor response1 (tir1) auxin signaling $F$ box protein 1 ( $a f b 1$ ) afb2 afb3 quadruple mutant) and transport (pinformed 1 (pin1) pin3 pin4 pin7 quadruple mutant) that will be further described in this review, which indicates that the auxin synthetized by YUC is critical for embryogenesis (Cheng et al., 2007).

It has been found that the modulation of the auxin biosynthetic genes (i.e., YUC1, 2, 4, and 10) is controlled by transcription factors such as LEC2 during somatic embryogenesis and particularly, it was described that YUC4 is a direct target of LEC2 (Stone et al., 2008; Wojcikowska et al., 2013). This indicates that regulation of the expression of key auxin biosynthetic genes by transcription factors is one of the mechanisms that modulate the hormone levels in Arabidopsis.

In maize, the seed is the organ that accumulates the greater content of IAA and most of the free auxin is synthesized in situ by the Trp-dependent auxin pathway. Compared to the $11 Y U C$ genes identified in Arabidopsis, only four YUC-like genes have so far been identified in maize (Bernardi et al., 2012), (Table 1). The first evidence of the relevance of TAR and YUC function in maize emerged from two parallel works based on the study of the expression pattern of these genes in $m n 1$ mutant. This mutant displays a reduced IAA content in the seed, and despite a higher expression of $Z m T A R$ than $Z m Y U C 1$ (in both mutant and wild type), only the ZmYUC1 showed a reduced level of expression in the mutant, suggesting a key role of this gene in auxin biosynthesis (Chourey et al., 2010; Le Clere et al., 2010). In maize, three of the TAR orthologs are highly expressed in the endosperm (Bernardi et al., 2012), while of the four YUC orthologs, only ZmYUC1 is mainly expressed in this tissue (Chourey et al., 2010; Le Clere et al., 2010), and it was reported recently that its expression correlates with IAA accumulation (Bernardi et al., 2012). Moreover, it was observed that in order to obtain an altered seed phenotype in Arabidopsis it is necessary to produce a quadruple $y u c$ mutant (as described in the first part of this section); however, in maize the single mutation in $Z m Y U C 1$ is sufficient to cause alteration in seed phenotype (Bernardi et al., 2012). This observation permits to speculate that, with respect to Arabidopsis, the $Y U C$ genes of maize show a higher tissue-specificity, while they are largely redundant in Arabidopsis.

Several mutants defective in auxin biosynthetic genes were identified in maize, i.e., orange pericarp (Wright et al., 1992); vanishing tassel2 (Phillips et al., 2011) that is homologous to TAA1; sparse inflorescencel (Gallavotti et al., 2008) and defective endosperm 18 (Torti et al., 1986; Bernardi et al., 2012) both homologous to AtYUC. Of these, the only mutant showing defective phenotype in seed is de18. The knockout mutation of ZmYUC1 in the mutant de18 still retains a high level of TAR despite a decrease in IAA during early endosperm development (1-7\% respect to wild type) suggesting that TAR and YUC may act on the same pathway also in maize seed (Bernardi et al., 2012).

The orange pericarp (orp) mutant, which is defective in Trp-synthesis originating from indole, produces plants that are 
Table 1 | Genes involved in the hormonal control of seed development in Arabidopsis and maize.

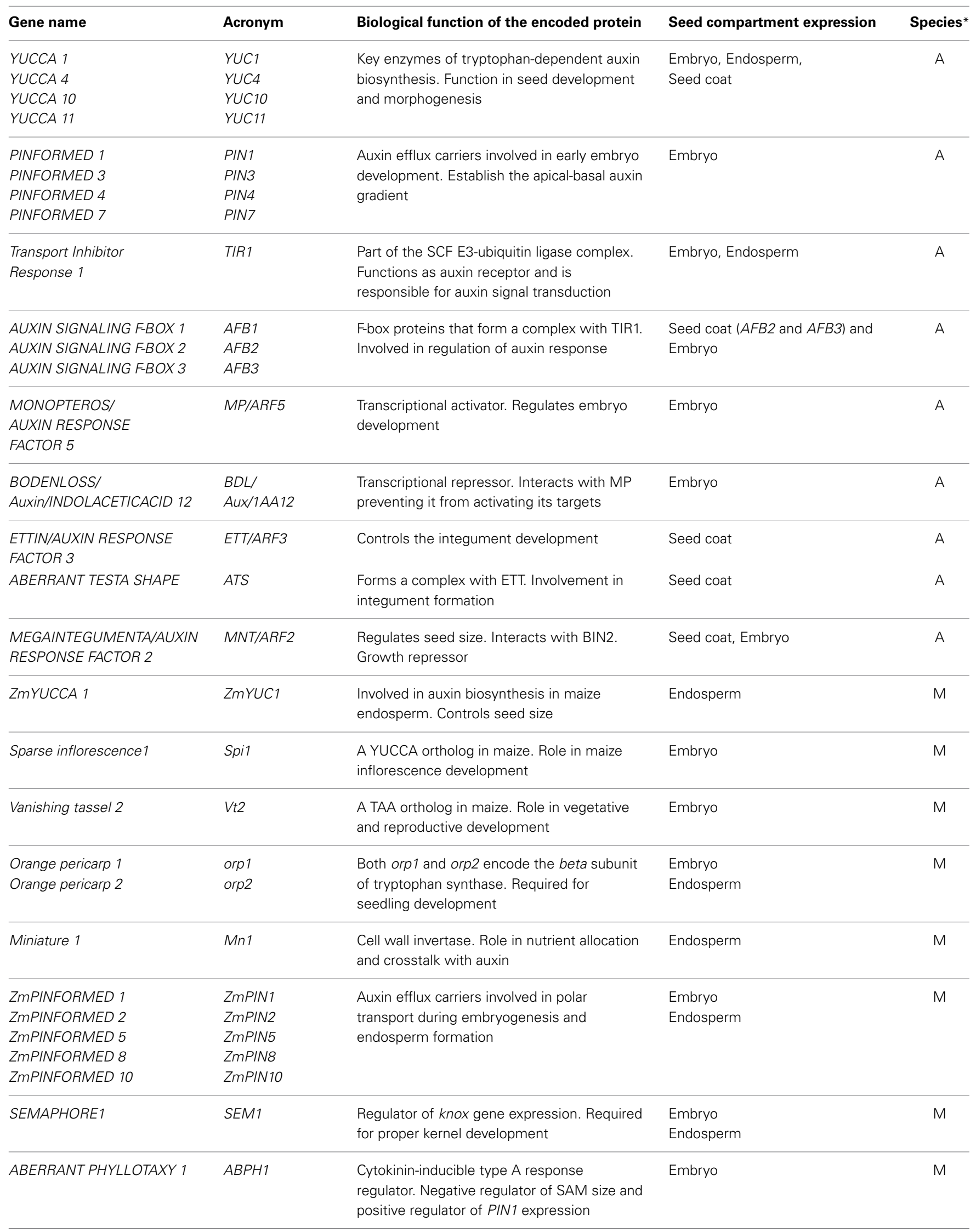


Table 1 | Continued

\begin{tabular}{|c|c|c|c|c|}
\hline Gene name & Acronym & Biological function of the encoded protein & Seed compartment expression & Species* \\
\hline $\begin{array}{l}\text { Histidine phosphotransfer } \\
\text { proteins }\end{array}$ & AHPS & $\begin{array}{l}\text { Cytokinin signal transducers. Regulate seed } \\
\text { size }\end{array}$ & Endosperm, seed coat & A \\
\hline Histidine Kinase & $A H K$ & Cytokinin receptor. Regulates seed size & Seed coat & A \\
\hline Response Regulators & ARRs & $\begin{array}{l}\text { Targets of the AHPs. Together with cytokinin } \\
\text { response proteins regulate endosperm } \\
\text { development }\end{array}$ & Endosperm & A \\
\hline SHRINK/CYP72C1 & SHK1 & $\begin{array}{l}\text { Decreases brassinosteroids levels. Regulates } \\
\text { cell division and seed size }\end{array}$ & Embryo Endosperm, Seed coat & A \\
\hline $\begin{array}{l}\text { CITOKININ OXYDASE } 1 \\
\text { CITOKININ OXYDASE } 2 \\
\text { CITOKININ OXYDASE } 3\end{array}$ & $\begin{array}{l}\text { CKX1 CKX2 } \\
C K X 3\end{array}$ & Regulate seed size and weight & Endosperm & A \\
\hline DWARF 5 & DWF5 & $\begin{array}{l}\text { Endoplasmic reticulum transmembrane } \\
\text { protein involved in brassinosteroids signaling }\end{array}$ & Embryo, endosperm, seed coat & A \\
\hline ZmHistidine kinase & $\begin{array}{l}Z m H K 1 \\
Z m H K 1 a 2 \\
Z m H K 2 \\
Z m H K 3 b \\
Z m H K 2 a 2\end{array}$ & $\begin{array}{l}\text { Cytokinin receptor-like genes. Control seed } \\
\text { size }\end{array}$ & Embryo & M \\
\hline DE-ETIOLATED 2 & DET2 & $\begin{array}{l}\text { Gene of brassinosteroids biosynthesis. } \\
\text { Controls embryo development, seed size and } \\
\text { embryo cell number }\end{array}$ & Embryo, Endosperm & A \\
\hline $\begin{array}{l}\text { BRASSINOSTEROIDS } \\
\text { INSENSITIVE } 1 \\
\text { BRASSINOSTEROIDS } \\
\text { INSENSITIVE } 2\end{array}$ & $\begin{array}{l}B R / 1 \\
B I N 2\end{array}$ & $\begin{array}{l}\text { Protein kinase, regulate brassinosteroids and } \\
\text { phosphorilatesARF2. Growth Repressor }\end{array}$ & Seed coat, Endosperm & A \\
\hline $\begin{array}{l}\text { BRASSINAZOLE- } \\
\text { RESISTANT } 1\end{array}$ & $B Z R 1$ & $\begin{array}{l}\text { Positive brassinosteroid-signaling protein. } \\
\text { Phosphorylated by BIN2 }\end{array}$ & Endosperm & A \\
\hline ZmStarch synthase I & $Z m S S I$ & Starch synthase induced by ABA & Endosperm & M \\
\hline
\end{tabular}

Only the genes mentioned in the text are showed. ${ }^{*} A$, Arabidopsis; $M$, Maize.

seedling lethal that can be partially rescued by supplying Trp, and accumulates indole and anthranilate (Wright et al., 1992). The fact that this mutant still produces auxin provided the first evidence that also a Trp-independent biosynthesis occurs in maize.

\section{Auxin polar transport}

The role exerted by auxin in the regulation of plant growth strongly depends on its characteristic polar transport. Plants have evolved a unique mechanism of directional cell-to-cell transport of this growth regulator, determinant for the generation of a polarized embryonic axis. The relevance of the apical-basal axis establishment is that it will determine the body plan of the adult organism. Auxin transport is realized by the PIN efflux transporters, the auxin influx carriers (AUX/LAX1 family) and the PGP proteins belonging to the ABCB transporter superfamily (Bennett et al., 1996; Petrasek et al., 2006). The polar subcellular localization of the carriers (influx/efflux) establishes the directional flow of auxin. In Arabidopsis there are eight genes encoding
PIN proteins (PIN1-8), of which only PIN1, PIN3, PIN4, and PIN7 are expressed in the embryo. Relocation of PIN1 and PIN7 has been shown to be crucial for embryo polarity establishment (Friml et al., 2003). Although the upstream mechanisms directing the polarization of auxin during embryogenesis are still practically unknown, it was shown that 24 -h after fertilization auxin peaks in the funiculus, the chalaza, and the micropyle of the ovule (but not in the valve), which indicates that the increase in auxin levels in the young seeds is probably due to a maternal origin (Dorcey et al., 2009). Friml et al. (2003) described through the analysis of the DR5rev::GFP marker line (a synthetic promoter that responds to auxin response factors) an accumulation of auxin in the apical cell of the embryo, just after the first divisions of the zygote, while a weak signal was detected in the suspensor. Later on during development, auxin signaling is localized in the upmost suspensor cells. At later stages of embryogenesis, auxin signal is detected at the tips of the developing cotyledons and provascular veins. Thus, auxin seems to determine the division 
patterns and specification of the cells derived from the zygote, and this pattern is determined by the activity of the PINs. PIN1 and PIN7 are required in the process of early embryo development. In fact, their asymmetric subcellular localization has been considered responsible for controlling polar auxin flow in postembryonic development (Friml et al., 2003), (Figure 2A). PIN7 is localized in the apical membranes of suspensor cells, while PIN1 localizes in pro-embryo cells, first in a non-polarized manner, while later, at the globular stage, it is recruited to the basal membrane. PIN7 polarity is then reversed, facing the basal membrane of suspensor cells. The polarization of PIN1 and reversion of polarity of PIN7 correlate with an apical-basal reversion of the auxin gradient (Friml et al., 2003). The biological function of the PINs in Arabidopsis seed development has been clarified by analyzing the phenotype of their mutants. A high percentage of embryos in pin 7 mutant do not correctly establish the apical-basal auxin gradient. Morphologically, the mutant embryo shows defects at the proembryo stage resembling those of $m p$ and $b d l$ mutations (see details below), bearing filamentous structures at late stages of embryo development. However, in many cases pin 7 mutants recover at globular stage, corresponding to the moment when PIN1 protein starts to be localized at the basal part of the cellular membrane and PIN4 expression increases. pin1 mutants also display defects at the basal embryo pole. Higher order mutants were generated by combining PINs single mutants, specifically expressed in the embryo (pin1, pin3, pin4, and pin7). The severity of the phenotypes increased additively as higher order mutants were generated. The quadruple mutant pin1 pin3 pin 4 pin 7 is the combination that displayed the most severe phenotype. These mutants, depending on the genetic background of the ecotype, can manifest embryo lethality or, when the embryo survives, will generate a plant with severe apical defects and nonfunctional or absent roots. The severity of the phenotype showed by these multiple mutants indicates the existence of some functional redundancy among the different PINs in the embryo (Friml et al., 2003).

In the seed of maize, a gradient of auxin might be responsible for a correct differentiation of both embryo and endosperm (Forestan et al., 2010). The switch from the apical to basal membrane localization of $Z m P I N 1$ proteins characterizes the coleoptilar stage and the following establishment of an auxin flux from both the differentiated scutellum and the shoot apical meristem (SAM) that is responsible for the differentiation of embryonic roots. The final stage, in which auxin polar transport is involved during embryogenesis, is the formation of leaf primordia, suggested by $Z m$ PIN1 localization in the subapical region of the meristem (Forestan et al., 2010) (Figure 2B).

Among the auxin transport carrier genes known in Arabidopsis, the PIN family of efflux carriers has been extensively studied in maize (reviewed in Forestan and Varotto, 2012). In particular, 12 PIN genes, 2 PIN-like and $1 A B C B$ were identified (Forestan et al., 2012). ZmPIN1, ZmPIN2, ZmPIN5, and $Z m P I N 10$ had overlapping expression during early seed development and their transcripts were localized in different subcellular domains. ZmPIN8, which was up-regulated in all the seed stages analyzed, was expressed in BETL cells, maternal chalazal tissues and aleurone layer (Forestan et al., 2012). In the

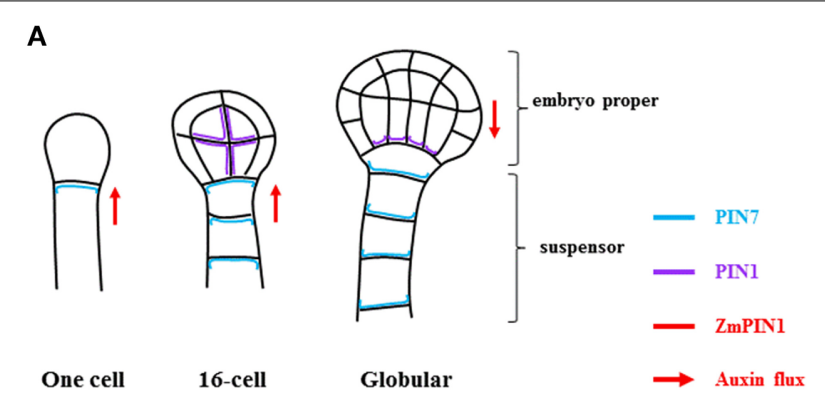

B
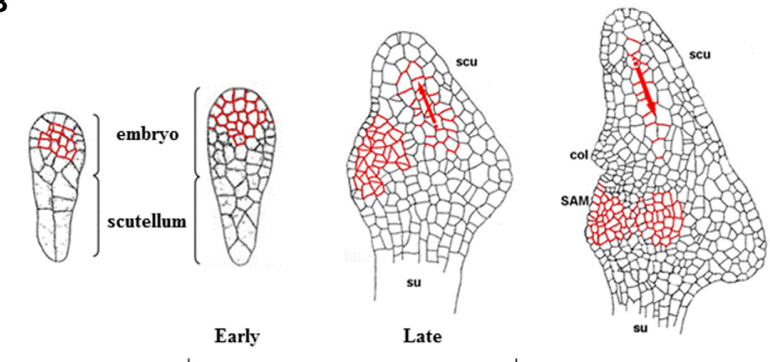

Proembryo

Transition

Coleoptilar

FIGURE 2 | Auxin transport during the embryogenesis development of Arabidopsis and maize. (A) Schematic representation of auxin transport during embryo development in Arabidopsis. In early embryo (one-cell stage to 16-cell stage in the figure), PIN7 (blue) is expressed in the suspensor cells localizing to the apical membranes, mediating auxin transport toward the proembryo. During the octant (not shown) and 16-cell stage, all proembryo cells express PIN1 (purple), which is evenly distributed along the inner cell membranes and not polarly localized. Later, during the transition to the globular stage, the subcellular localization of PIN1 becomes polar, facing the basal membranes. Simultaneously and similarly, the polarity of PIN7 localization is reversed, now localized at the basal membrane of suspensor cells. The localization of PIN1 and PIN7 in the basal membranes establishes an apical-basal flux of auxins that will be maintained throughout the life cycle of the plant (adapted from Friml et al., 2003; Weijers and Jurgens, 2005; Nawy et al., 2008). (B) Model for the ZmPIN1-mediated auxin transport during early stages of maize embryogenesis. Medial longitudinal sections of maize embryos at proembryo, transition and coleoptilar stages are shown. The ZmPIN1 protein (red) localizes in embryo plasma membranes. After the first division of the zygote, several cell divisions in different planes lead to the formation of the small embryo and the larger suspensor (proembryo stage). At this stage, auxins accumulate in the endosperm above the embryo but not in the embryo itself (not shown), and ZmPIN1 localizes at the cell boundaries of the undifferentiated proembryo core, without any polarity. Later, adaxial/abaxial polarity is established by the outgrowth of the scutellum at the abaxial side of the embryo (early transition stage). ZmPIN1 is polarly localized in the apical anticlinal membranes, marking the provascular cells of the differentiating scutellum, indicating an auxin flux toward the tip of the single maize cotyledon (late transition stage). At the coleoptilar stage there is the switch from apical to basal gradient of ZmPIN1, followed by a change of the auxin flux (adapted from Forestan et al., 2010; Chen et al., 2014). col, coleoptile; SAM, shoot apical meristem; scu, scutellum; su, suspensor. In both $A$ and $B$ the red arrows indicate the auxin efflux mediated by PINs.

same work it was proposed that some $Z m P I N$ genes could be subjected to sub-functionalization. Some conserved mechanisms in Arabidopsis and maize are found during embryogenesis where $Z m P I N 1 a-c$ appeared to have a redundant function as 
previously reported for Arabidopsis PIN genes (Vieten et al., 2005) (Figure 2).

In a recent work by Chen et al. (2014) it was shown that the auxin signaling from the endosperm was important to pattern embryo development during early embryogenesis in maize. More specifically, the auxin signal detected at the surface of the adaxial embryo was correlated to the specification of embryo proper, SAM and scutellum. As previously mentioned, the ZmPIN1 signals were polarized first in the apical and in the basal membrane of epidermal L1 cell layer suggesting an auxin flux from these cells to the inner layers (also detailed in Figure 2). Finally, the same authors suggested a new function for the ESR during the early stages of development, being responsible for preventing the auxin flux from the endosperm to the embryo.

Concerning the endosperm specification, a gradient drop off specifies the aleurone fate maintaining the outer layer above a specific IAA threshold. Indeed, in normal maize endosperm, the auxin concentration is high at the endosperm margin and lower in the center. In the presence of NPA, an auxin transport inhibitor, auxin accumulates above this threshold in many cell layers, resulting in a multilayered aleurone (Becraft and Asuncion-Crabb, 2000; Becraft and Yi, 2011). A further mutant that shows a reduction of auxin transport is semaphore1 (sem1). sem1 shows a dwarf phenotype with defects also in endosperm and embryo patterning (Scanlon et al., 2002) but the gene mutation responsible for the alteration in the polar auxin transport has not yet been identified.

\section{Signal transduction}

At the molecular level, auxin response is mediated by the action of AUXIN RESPONSE FACTORS (ARFs). The ARFs are transcription factors that recognize specific sequences termed Auxin-Response Elements (AuxREs) present in the promoter of auxin-responsive genes, activating or repressing their transcription (Abel and Theologis, 1996; Ulmasov et al., 1999). However, the ARFs do not seem to be able to regulate gene expression in response to auxin by themselves, but require interaction with the AUXIN/INDOLE-3-ACETIC ACID (AUX/IAA) proteins, which constitute the repressors of auxin signaling (Kim et al., 1997). Aux/IAAs function as transcriptional repressors by binding and sequestering the ARFs. The degradation of the Aux/IAA proteins is induced by auxin (Guilfoyle and Hagen, 2007). Briefly, the Fbox protein Transport Inhibitor Response 1 (TIR1), which has been identified as an auxin receptor (Dharmasiri et al., 2005; Kepinski and Leyser, 2005), interacts with the E3-Ubiquitin ligase Skp1/Cullin/F-box (SCF) complex, generating the SCF ${ }^{\mathrm{TIR} 1}$ complex, and determining the substrate specificity toward the Aux/IAA proteins. These proteins are thus ubiquitinated, and marked as substrates for proteasomal degradation (Tan et al., 2007). Dharmasiri et al. (2005) described three additional genes, $A F B 1,2$, and 3, which encode F-box proteins also interacting with the SCF-complexes. In Arabidopsis, TIR1 and AFB1 are moderately expressed during embryogenesis, while $A F B 2$ and 3 expression is high. The generation of high order mutants for the four genes resulted in a progressive decrease in auxin response, as well as an increase in the severity of the defects in development. The severe effect of the quadruple mutation is manifested in the lack of root, the disappearance of hypocotyl, and often by the formation of a single cotyledon resembling bdl or $m p$ mutants.

Genome-wide analyses on the maize reference genome were performed to identify the $A u x / I A A$ (Wang et al., 2010b) and $A R F$ gene families in maize (Liu et al., 2011; Xing et al., 2011; Wang et al., 2012). The 31 identified $Z m A u x / I A A$ genes showed a putative expression (based on EST mining) in different tissues and organs that suggests a temporal and spatial pattern of regulation. The 31-36 ZmARF are also known to have a tissue-specificity that changes during plant development (Wang et al., 2010b, 2012; Liu et al., 2011; Xing et al., 2011). Each ZmARF possesses a sister pair due to chromosomal duplication of the maize genome, and they are distributed in all the chromosomes except chromosome 7 (Xing et al., 2011; Wang et al., 2012). Xing et al. (2011) found that about half of the $Z m A R F$ genes identified have an auxin responsive element in their promoter regions and 18 were predicted to be targets of small RNAs. Furthermore, in the same work, seven $Z m A R F$ genes were constitutively expressed in developing embryo suggesting the importance of auxin signaling during embryo formation in maize. Despite the genomic information, there is still a lack of knowledge about the functional role of these auxin-related factors in maize.

In Arabidopsis 23 ARFs and 29 Aux/IAA were identified (Okushima et al., 2005). Of these, only three ARFs and one IAA have been characterized as having a role in seed and embryo development. ARF5/MONOPTEROS (MP) is an activator of auxin-responsive genes and constitutes a key element in the development process of the embryo. While $m p$ partial loss-of-function mutants have nearly normal embryo development, their reproductive program is compromised. The phenotype of $m p$ strong mutant alleles results in alterations of the basal body region of the embryo, such as malformation of the hypophysis and subsequent absence of the radicle and root meristem, already detectable from the octant stage of embryo development, frequently ending in an embryo lethal phenotype (Berleth and Jurgens, 1993; Hardtke and Berleth, 1998). The gene BODENLOSS (BDL) encodes IAA12. It was demonstrated that $b d l$ mutant, holding a gain-of-function mutation that stabilizes the BDL protein, has a phenotype similar to $m p$. The fact that the double mutant $b d l m p$ shows a similar phenotype places BDL and MP in the same pathway (Hamann et al., 2002). In fact, $B D L$ is co-expressed with $M P$ during early embryogenesis, and it was shown that this protein physically interacts with MP. These results indicate that BDL and $\mathrm{MP}$ are IAA-ARF interacting proteins, where in this interaction $\mathrm{BDL}$ prevents MP from activating its auxin responsive gene targets. After BDL degradation in response to auxin, the release of MP triggers the correct initiation of the basal body region in early embryogenesis (Hamann et al., 2002).

On the other hand, ARF3/ETTIN (ETT) controls the correct development of the integuments and thus, the seed coat. The ett mutant ovules present the same alterations as the aberrant testa shape (ats) ones, where inner and outer integuments grow together fused in a single wide structure, resulting in rounded, aberrant-morphology seeds, variable in size (Kelley et al., 2012). The authors show that ETT and ATS are able to interact, and propose a model in which, upon integument initiation, ATS-ETT complex accumulates in the ovule, in the abaxial layer of the inner 
integument, where they negatively regulate $P I N 1$, proposing that these two proteins participate together in auxin signaling during seed development (Kelley et al., 2012).

Finally, megaintegumenta (mnt) mutants, defective in ARF2, present larger seeds than wild-type plants due to the formation of a bigger integument (Schruff et al., 2006). Despite the fact that the phenotype of the mnt/arf 2 mutant has been already characterized, the ARF2 targets that control seed development are still unknown. In Arabidopsis, the mechanism by which ARF2 is activated has been elucidated and involves a phosphorylation mediated by the protein kinase BRASSINOSTEROID-INSENSITIVE 2 (BIN2), which in turn is regulated by brassinosteroids (Vert et al., 2008). In the $m n t / a r f 2$ mutant, seed size and weight are dramatically increased. The enlarged seed coat is due to the presence of extra cells in the integuments before fertilization, generated by extra anticlinal cell divisions. The embryo is also bigger than the wild type, but not the endosperm. Surprisingly for integument mutants, mnt/arf 2 does not show female infertility. Given that the mnt/arf2 lesion causes other pleiotropic effects on vegetative and floral development, Schruff et al. (2006) conclude that MNT/ARF2 is a repressor of cell division and organ growth.

\section{Nutrient allocation and auxin in maize endosperm}

The role of sugars in controlling auxin biosynthesis and metabolism in both maize and Arabidopsis is well known (Le Clere et al., 2010; Sairanen et al., 2012; Figure 3). In maize, auxinsugar crosstalk involves other aspects peculiar to this Monocot: nutrient accumulation and endoreduplication in the endosperm. The transfer cells or BETL, as the major site of cross-talk between maternal (chalazal) and filial tissue (endosperm and embryo), is essential for nutrient intake and correct endosperm development. Indeed, the altered morphology of BETL is a characteristic of mutants with reduced seed mass such as de18 (Torti et al., 1984), $m n 1$ (Kang et al., 2009), and reduced grain filling1 (Maitz et al., 2000). It has been observed that in the situation of abnormal development of BETL the transport of auxin, and presumably its accumulation, is impaired. Indeed, de18 mutant exhibits low levels of ZmPIN1 in the transfer cells with respect to the wild type (Forestan and Varotto, 2010).

Zeins are the main storage proteins of maize kernels, constituting about $70 \%$ of total protein content in endosperm. An increase in zein synthesis was observed at both transcript and protein level after exogenous auxin treatment (Lur and Setter, 1993a). In the defective kernel18 mutant (dek18), that is defective in auxin accumulation, 12 and $14 \mathrm{KDa}$ zeins were found to correlate with auxin content. Indeed, at $20 \mathrm{DAP}$, these proteins were present in the wild type and in the mutant treated with exogenous auxin and not in the dek18 mutant (Lur and Setter, 1993b). Whereas the interaction between zeins and auxin has not been proved, the sugar-hormone crosstalk in maize is well known (Chourey et al., 2010; Le Clere et al., 2010). IAA synthesis seems to be required for grain filling in maize and this process is related to the cell wall invertase activity. In $m n 1$, which is a small seeded mutant defective in invertase, the low sugar content correlates with the low transcript level of $Z m Y U C 1$ during endosperm development (Le Clere et al., 2010). Indeed, the presence of glucose increased the expression of $Z m Y U C 1$ in cultured kernels (Le Clere et al.,

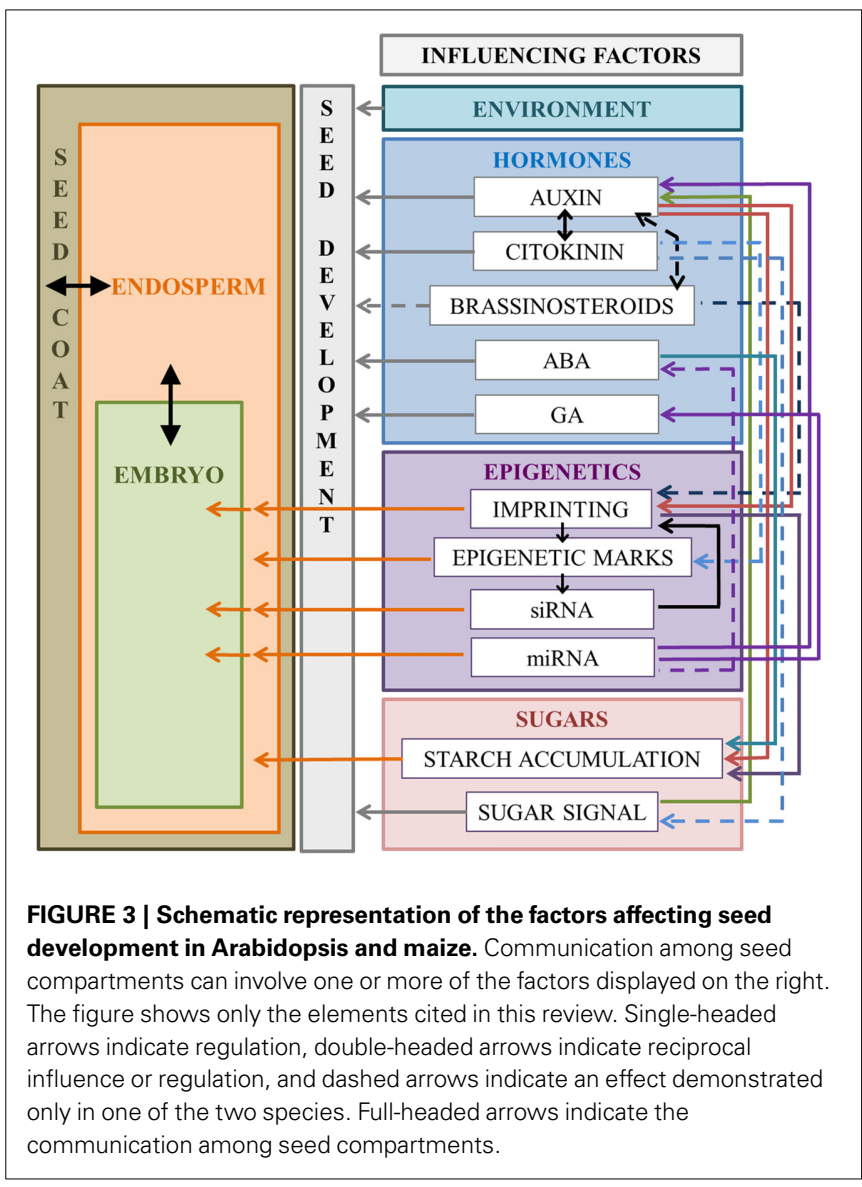

2010). Forestan et al. (2010) showed that IAA accumulation in the three endosperm compartments (BETL, aleurone and ESR) occurs shortly before the starch accumulation phase. The invertase inhibitor ZM-INVINH1 has been reported to bind cell wall invertase during kernel development in maize and is localized to the ESR (Bate et al., 2004). This evidence suggests that invertase activity, together with auxin transport, has a key role in the regulation of events that control carbon partitioning during early kernel development. The evidence that $Z m Y U C 1$ is regulated by hexose sugars, in particular glucose is in agreement with the data reported in Arabidopsis (Hartig and Beck, 2006).

During the early phases of endosperm development, endoreduplication and the synthesis of storage compounds are tightly interconnected (Sabelli and Larkins, 2009). There is limited information on how phytohormones control the endoreduplication in maize. It was shown that the increase of IAA in the late stage of seed development is coincident with the onset of endoreduplication (Lur and Setter, 1993a). Furthermore, analysis of auxin levels in several dek mutants indicated a positive correlation between IAA and nuclear size (Lur and Setter, 1993b). The same evidence was found studying de18 mutant (Bernardi et al., 2012). The low auxin accumulation in the early stages of development of this mutant causes a delay in endoreduplication and a reduced ploidy level with respect to the wild type.

In two recent works about the dissection of the maize seed transcriptome many genes related to hormone metabolism were 
found enriched, particularly in embryo (Lu et al., 2013; Teoh et al., 2013). Transcription factor analysis on maize seed evidenced that most of the highly expressed genes in the embryo are involved in epigenetic regulation (i.e., methyltransferases and acetyltransferases) and hormone signaling pathways (i.e., ARF and Aux/IAA) (Lu et al., 2013). The role of epigenetics in the control of seed development is briefly discussed in Section Epigenetic Control of Endosperm Development by Genomic Imprinting.

\section{ROLE OF THE OTHER PHYTOHORMONES ON SEED DEVELOPMENT}

Although auxin plays a principal role in the regulation of embryo patterning and endosperm development, other hormones have been found to participate in the control of seed development. Their functions in this developmental process and the links between them are briefly discussed in the following sections.

\section{The role of cytokinins}

The activity of Cytokinins (CKs), together with auxin, is especially linked to growth promotion by cell division, development and differentiation (Bishopp et al., 2011; Vanstraelen and Benkova, 2012). Although the biosynthetic pathway and transmission of the signal are quite well described (Hwang et al., 2012), the function of CKs in the seed has still not been exhaustively characterized. In Arabidopsis, the limited existing knowledge comes from a few reports (Werner et al., 2003; Garcia et al., 2005; Day et al., 2008). Day et al. (2008) identified the Histidine-containing phosphotransfer proteins genes (AHPs) as the genes preferentially activated by CKs in Arabidopsis. After being phosphorylated by the CKs-receptors (AHKs), the AHP proteins transduce the CKsignal by entering the nucleus and transferring the phosphate group to the Arabidopsis response regulators (ARRs). The ARR proteins constitute a class of regulators in the cytokinin signaling. They comprise the type-A proteins that are normally negative regulators of CKs signaling, and the type-B that positively regulate gene expression. They can directly bind DNA through the MYB-like domain, and contribute to the outputs of the cytokinin signaling through protein-protein interactions by their glutamine (Q)-rich domain. The CYTOKININ RESPONSE FACTOR (CRF) proteins rapidly accumulate in response to CKs. Their function largely overlap with the type-B ARRs, indicating that CRF and ARR belong to a two-component system for the transmission of CKs signaling in the regulation of the development of embryo, cotyledons and leaves (Rashotte et al., 2006). The B-type $A R R$ genes (ARR21, ARR19, ARR18, ARR8) together with the CRF2 and $C R F 3$ genes are preferentially expressed in the endosperm (Day et al., 2008).

Studies of the genes related to CKs production have shown that during the first stages of seed development their expression is principally associated to an effect of the hormone on the development of endosperm and seed coat. These results suggest that the control of seed size would involve a crosstalk occurring between maternal and zygotic tissues (Garcia et al., 2005). Genetic analyses of CK synthetic genes (cytokinin oxidases, CKXs) -AtCKX1 and $A t C K X 3$ - have indicated that in the corresponding mutants the size of the seed, as well as the embryo, was increased (Werner et al., 2003). Similar phenotypes were found observing the triple mutant of the cytokinin receptors ahk2 ahk3 ahk4 (Riefler et al.,
2006). The effect of an increase in both embryo and seed size was suggested to be under control of maternal and/or endospermal genotypes (Riefler et al., 2006).

Recently, CKs were elucidated to have an important role in the integration of epigenetic and genetic control of seed development. Li et al. (2013) characterized CKX2 as target of IKU that, as mentioned before, has a relevant role in the promotion of endosperm cellularization, controlling seed size. Several works have been conducted in maize because of the high level of CKs detectable in the seed and the relative ease of study due to the seed size. In most of these studies the relative abundance of the hormone at the early stages of endosperm development and embryo differentiation was reported (Jones, 1990; Lur and Setter, 1993a,b; Dietrich et al., 1995; Brugiere et al., 2003; Veach et al., 2003; Rijavec et al., 2009). Studies on gene transcription in different stages of caryopsis development showed that the genes encoding for enzymes involved in the synthesis of CKs are expressed mainly in endosperm, pedicel and embryo soon after pollination. In the pedicel/placental chalazal/basal endosperm region, CKs levels were 2-3 times higher than in the rest of the seed (Brugiere et al., 2003). At a later stage of seed development, CKs become detectable also in the BETL (Brugiere et al., 2008; Smehilova et al., 2009; Vyroubalova et al., 2009; Rijavec et al., 2011). Immunolocalizations and in situ hybridizations showed that CKs are synthesized in certain regions of the seed, but they are also transported from the maternal tissue through the pedicel to the endosperm (Zhang et al., 2009b; Rijavec and Dermastia, 2010). The authors also found that CKs accumulate in the placenta-chalazal cell layer and are able to promote Programmed Cell Death (PCD).

Similarly to Arabidopsis, the main role of CKs detected in the caryopsis of maize is establishing seed size, by promoting endosperm cell divisions. A relationship was elucidated between CKs accumulation and/or activation, and cyclin activity. In respect to Arabidopsis, in which CKs have an effect only on CycD3 activity (Riou-Khamlichi et al., 1999), in maize the CKs affect CycD3 and CycD2 (Gutierrez et al., 2005).

A study on the localization of auxin and cytokinins during early seed development elucidated the role of these two antagonistic hormones. At 6-8 DAP the CKs were detected in both the BETL region and the ESR, while the signal was very low in the embryo (Chen et al., 2014). This evidence correlates with the fast cell division and growth at both apical and basal part of the endosperm. Later in development (9-10 DAP) CKs signal is mainly localized in the epidermis of the scutellum and in the SAM. The contemporary localization of auxin and CKs during early embryo development is different at the scutellum tip, where IAA signal is stronger than that of CKs. In Arabidopsis, transient and antagonistic interaction between auxin and cytokinins is critical for specifying the root-stem cell-pool that will determine the definition of the root-stem axis. Auxin, through a feedback mechanism, is responsible for the repression of CKs signaling in this region (Muller and Sheen, 2008). It might be possible that a similar crosstalk occurs in the tip region of the scutellum of maize: the high auxin response at the abaxial tip region may repress cytokinin activity (Chen et al., 2014). 
In a more recent study the functional characterization of seven ZmHistidine kinase $(\mathrm{ZmHK})$ genes, encoding the cytokinin receptors, was performed (Wang et al., 2014). Arabidopsis transgenic lines expressing each of the $Z m H K$ genes showed a reduction in seed size with respect to the normal. This result suggests that $\mathrm{ZmHKs}$ function as repressors of seed development.

\section{The role of brassinosteroids}

Brassinosteroids (BRs) are plant steroid hormones involved in several developmental programs, including seed development. They function in the pathway that regulates ovule number and seed size and shape, in some cases complementing CKs and auxins. They also participate in the regulation of seed germination, by antagonizing the inhibitor effect of ABA (Zhang et al., 2009b), and being synergic to gibberellins (Leubner-Metzger, 2001).

The mechanisms by which BRs control seed development are still elusive. Many studies on BRs signaling have been performed on BR-deficient mutants in rice (Hong et al., 2005; Tanabe et al., 2005; Morinaka et al., 2006; Jiang and Lin, 2013). Different works demonstrated the relevance of BRs on seed size determination also in Arabidopsis, using BR-deficient or insensitive mutants (Choe et al., 2000; Li et al., 2001; Jiang et al., 2013; Jiang and Lin, 2013). Arabidopsis mutants deficient in BRs (i.e., dwarf5, $d w f 5$; dwf11; shrink1-D, shk1-D; detiolated2, det2; BR-Insensitive1, bri1) produce dwarf phenotypes and smaller and fewer seeds (Chory et al., 1991; Choe et al., 2000; Takahashi et al., 2005; Jiang and Lin, 2013).

The control of seed development by BRs is mainly exerted through the function of the protein BRASSINAZOLE RESISTANT1 (BZR1). The activity of BZR1 varies according to its state of phosphorylation, dependent on the presence of BRs and mediated by the BIN2 kinase, which acts as a negative regulator (Li and Nam, 2002; Wang et al., 2002; Yin et al., 2002). BZR1 acts as a master regulator, from which a network of links extends to proteins acting in the different pathways of seed development and determination: ARF2, TRANSPARENT TESTA GLABRA2 (TTG2) and TTG16 regulating integument development; SHB1, IKU1, and 2, MINI3 together with AP2 and the MADS-box AGL61, 62, and 80 regulating endosperm development; and epigenetic regulators of endosperm development and paternal imprinting such as FIS2, MEA, FIE, MET1, SWN, and MSI1 (Sun et al., 2010; Jiang et al., 2013; Jiang and Lin, 2013). Indeed, the model proposed by Jiang and Lin (2013) indicates that BRs control the development of embryo and endosperm (and subsequently seed development) by regulating the expression of these genes through the direct or indirect action of BZR1.

The altered seed phenotype that $d w f 5$ and $\operatorname{shk} 1-D$ mutants display indicates that BRs are also involved in seed shape determination (Choe et al., 2000; Takahashi et al., 2005). Thus, it has been observed that seed elongation requires BRs production and signaling in the maternal tissues (integuments) after fertilization. This aspect was especially evident in the det 2 mutant, where the cell length of the integuments was significantly reduced and partially rescued by exogenous application of BRs (Jiang et al., 2013).

Summarizing, in Arabidopsis it has been shown that the production of BRs in the embryo/endosperm is sufficient to increase seed volume, while they regulate seed size by an independent mechanism that involves BR production and signaling in the seed coat. How these hormones trigger different, localized behaviors in the different seed compartments still remains unknown (reviewed in Jiang and Lin, 2013).

Concerning maize, the information about BRs is extremely limited, and nothing is known about the conservation of the mechanism of action with respect to Arabidopsis and rice (Salas Fernandez et al., 2009). Hartwig et al. published one of the pioneering works in 2011. They characterized the mutant nana plant 1 (na1), which is a mutant on $Z m D E T 2$, the Arabidopsis ortholog of DET2 (Hartig and Beck, 2006; Hartwig et al., 2011). The phenotype of this mutant possesses all the characteristics of a BRdeficiency mutant, and shows the typical dwarfism. This work is complemented by a few other studies in which three additional genes involved in BRs biosynthesis and signaling were isolated (Tao et al., 2004; Liu et al., 2007b; Makarevitch et al., 2012). However, no data are available about the specific effect of BRs on maize seed development, so this is an attractive field to be explored.

\section{The role of abscissic acid and gibberellins}

The action of Abscissic acid and Gibberellins (GAs) on seed development is strictly correlated and antagonistic. As already mentioned, during the phase of seed maturation it is possible to define two important processes: the accumulation of nutrients in the endosperm (that will be used by the embryo during development and early phase of germination) and desiccation (that allow the embryo to tolerate hydric stress and terminate in the state of seed dormancy). Both processes are predominantly regulated by ABA. The concentration of this hormone increases during the late phase of seed maturation and is maintained until germination. In order to germinate, however, the seed must recover the water lost during maturation, since it is necessary to mobilize the resources for the embryo and activate enzymes and pathways for breaking of dormancy. This process, named imbibition, is regulated by the gibberellic acid. Hence, the ratio of ABA and GAs is determinant in the progression of seed maturation (Weber et al., 2005; Bethke et al., 2006; Seo et al., 2006; Liu et al., 2010).

The mechanism by which ABA controls the accumulation of food resources in the aleurone cell layer is based on the regulation of $\beta$-ZIP and DOF transcription factors (Vicente-Carbajosa and Carbonero, 2005; Monke et al., 2012). A study conducted by Karssen et al. (1983) and subsequently confirmed by Kanno et al. (2010) revealed that the biosynthesis of ABA occurs both in the maternal tissue and in the zygote. The synthesis of the hormone in the first compartment determines a primary peak of ABA accumulation, which is necessary to complete the process of embryo development. The final stages of embryo and endosperm formation correlate with a second peak of ABA, necessary to begin the process of seed desiccation and food storage in the aleurone layer (Kanno et al., 2010). Regarding other aspects of seed development, it is still unknown if ABA has additional functions in the zygotic compartments. In Arabidopsis, similarly to maize, it has been shown that the synthesis of starch and thus its accumulation begins at the early stage of seed development (Chen et al., 2011). During this process the synthesis of starch is regulated by 
phytohormones, such as ABA and IAA, with a major role played by ABA. It has been reported that the genes for starch metabolism (i.e., AGPase, SS, $D B E$, and $S B E$ ) are regulated by sugars (Rook et al., 2001; Bossi et al., 2009; Seiler et al., 2011). Moreover, interesting results by $\mathrm{Hu}$ et al. (2012) showed a correlation between ZmSSI (a sugar-regulated gene for starch-synthesis) and ABA during the endosperm filling stage. Identification of a sequence in the promoter of $Z \mathrm{mSSI}$ that is recognized by ABSCISIC ACID INSENSITIVE 4 (ABI4) allowed the characterization of the mechanism by which ABA regulates the expression of the gene. ABI4 would act as a transcriptional activator of $Z \mathrm{mSSI}$ in response to ABA treatment.

GAs, conversely to ABA, promote germination by mobilizing the resources necessary for embryo development (Koornneef et al., 1982). This is supported by the fact that after the cotyledon stage, when the events of PCD in the endosperm begin to leave space to the expanding embryo, some of the genes related with GA-biosynthesis are activated, followed by the activation of proteolytic enzymes and $\alpha$-amylases (Sreenivasulu and Wobus, 2013). The study of the synthesis of bioactive GAs during seed development revealed that the peak of GAs occurs just before that of ABA (Singh et al., 2010; Nadeau et al., 2011). High auxin concentration also triggers the production of bioactive gibberellin (Dorcey et al., 2009), (Figure 1).

\section{EPIGENETIC CONTROL OF ENDOSPERM DEVELOPMENT BY GENOMIC IMPRINTING}

Although the epigenetic mechanism of regulation is beyond the scope of this review, it is worth mentioning it, since it is still linked to hormones accumulation and coordination. In this context, a prominent role is exerted by the epigenetic mechanisms that determine the parent-of-origin specific gene expression, described as genomic imprinting. The regulation of gene expression by imprinting has been extensively studied in maize and rice, as Monocots, and in Arabidopsis, representing Eudicots (Hsieh et al., 2009; Luo et al., 2011; Waters et al., 2011).

The process by which a gene is imprinted involves the placement of epigenetic marks on its genomic sequence (i.e., DNA methylation) or in the nucleosomes (i.e., histone modifications). Different classes of methyltransferases can deposit the DNAmethylation marks, however, the methyltransferase operating in the endosperm is mainly the cytosine-DNA-methyltransferase MET1 (Law and Jacobsen, 2010). The action of DEMETER (DME) is antagonistic to MET1 as it removes the methylation marks from specific imprinted genes in maternal tissues allowing their expression (Choi et al., 2002; Gehring et al., 2006). Histone H3K27 tri-methylation is the epigenetic mark for silencing. The proteins that catalyze this modification belong to the Polycomb group of proteins (PcG). Genes like MEA/FIS1, FIS2, and FIE/FIS3 belong to the PcG, and exert a pivotal role on maintaining the pattern of gene expression in the endosperm. These proteins participate in the formation of the Polycomb Repressive Complex 2 (PRC2), contributing to the establishment of an imprinted state, thus controlling gene expression in the developing seed (Hennig and Derkacheva, 2009).

The process of imprinting takes place already during gametophyte formation (Reik and Walter, 2001; Feil and Berger, 2007;
Waters et al., 2013b). Epigenetic mechanisms involving small interfering RNAs (siRNAs), which are responsible for silencing of the complementary gene targets, have been suggested as having a prominent role in genome-wide hypomethylation of Arabidopsis endosperm (Hsieh et al., 2009, 2011; Bauer and Fischer, 2011). In particular, it has been shown that genomic demethylation by DME induces the production of siRNAs, in both Arabidopsis (Ibarra et al., 2012) and rice (Rodrigues et al., 2013). It has been observed that an extensive process of demethylation on Transposon Elements (TE) or repeats participates in the process of imprinting by affecting the neighboring genes (Choi et al., 2002; Gehring et al., 2006). Indeed, in Arabidopsis, one third of the imprinted genes are flanked by TEs (Bauer and Fischer, 2011; Gehring et al., 2011; Wolff et al., 2011). The global hypomethylation in the endosperm is likely originated from the central cell nucleus of the female gametophyte prior to fertilization (Ibarra et al., 2012). The major role of demethylation in female gametophyte (central cell) and male gametophyte (vegetative nucleus) is to produce siRNAs that are transported to the egg cell (in the female gametophyte) and the sperm cells (in the pollen) to reinforce the silencing of TEs (Gutierrez-Marcos et al., 2006; Bauer and Fischer, 2011; Ibarra et al., 2012). Given that, prior to fertilization the parental alleles are differentially methylated in each gametophyte, the triploid endosperm generated in the second event of fertilization will cope with a different state of methylation between the parental alleles. The different state of methylation between the alleles is believed to trigger the establishment of genomic imprinting in specific parental genes (Raissig et al., 2011). Interestingly, the control of gene expression by imprinting is important in the context of the determination of seed size and viability of the embryo (Xiao et al., 2003).

Despite that few imprinted genes are common between maize, rice and Arabidopsis, the mechanism that regulates parent-oforigin expression seems to be conserved between Monocots and Eudicots (Gutierrez-Marcos et al., 2006; Rodrigues et al., 2013). It is well established that the major site where the imprinted genes accumulate is the endosperm (Luo et al., 2011). Nevertheless, in both Arabidopsis and maize imprinted genes have also been identified in the embryo (i.e., maternally expressed in embryol, meel Jahnke and Scholten, 2009). The identity of the imprinted genes in both Arabidopsis and maize has been determined, in many cases, through advanced techniques of transcriptome deep sequencing and genome-wide search (Gehring et al., 2011; Waters et al., 2011; Zhang et al., 2011, 2014; Xin et al., 2013). These genes encoded proteins with a wide range of molecular functions, ranging from the regulation of pigmentation, starch metabolic pathways, protein storage, hormone responses, cell wall formation, transcriptional regulation, chromatin modification, and cytoskeletal function to mRNA regulation.

The distinct pattern of Maternally Expressed Genes (MEGs) and Paternally Expressed Genes (PEGs) ensures the proper evolution of seed development and is associated with specific stages of endosperm development (Raissig et al., 2013). In maize, the imprinted gene Meg1 is involved in nutrient allocation and has a role in controlling seed size (Costa et al., 2012). Meg1 positively regulates transfer cell specification and development, therefore increasing nutrient uptake. This effect is especially pronounced 
at 10 DAP, when a peak of auxin in BETL, ESR and aleurone layer coincides with the onset of nutrient accumulation for starch and zein storage protein synthesis (Lur and Setter, 1993a; Sabelli and Larkins, 2009; Forestan et al., 2010). The involvement of imprinted genes in hormone signaling pathways and transcriptional regulation of endosperm development is evidence of the importance of auxin in correct seed development (Xin et al., 2013). The role of imprinted genes (in particular MEGs) in driving the correct nutrient synthesis is coupled with the importance of the transport mediated by auxin. It is not surprising that PIN1 was identified as specific MEG (Xin et al., 2013). Interestingly, YUC10 orthologs in rice, maize and Arabidopsis were found to be exclusively paternally expressed, meaning that the function of YUC10 could be crucial for endosperm development (Waters et al., 2013b). The relevance of MEGs and PEGs in this stage of development is to facilitate the communication and coordination between endosperm, embryo and maternal tissues.

\section{miRNAs CONTROL OF SEED DEVELOPMENT}

Another relevant mechanism controlling gene expression during seed development is exerted by microRNAs (miRNAs). miRNAs are single-stranded RNA molecules of 21-22 nucleotides in length (with some exceptions) processed from a precursor molecule defined as pre-miRNA (Bartel, 2004). The RNA duplex is subsequently transported out of the nucleus, where the complementary sequence (called star) is removed to allow mature miRNA to be ready for action. The mature miRNA binds with perfect or imperfect complementarity to sites in the $5^{\prime}$ or $3^{\prime}$ untranslated regions (UTR) or coding sequences (CDS) of genes, causing its cleavage or translational repression (Grennan, 2008).

Plant microRNAs play important regulatory roles in many biological and metabolic processes, including development, hormone signaling, and responses to environmental stress (Reinhart et al., 2002). miRNAs are frequently grouped in families that have a specific set of transcript targets and appear to be evolutionarily conserved between plant species (Wu et al., 2009; Wang et al., 2011). It has been observed that miRNAs are expressed from early to later stages during seed development (Kang et al., 2009; Nodine and Bartel, 2010; Rubio-Somoza and Weigel, 2011). More specifically, they seem to be implicated in the control of embryogenesis and embryo patterning, also affecting the germination process (Seefried et al., 2014). Mutants lacking essential components of miRNA biogenesis and/or processing, manifest a severely compromised seed development or even lethality (Nodine and Bartel, 2010). The relevance of miRNAs function in the control of seed development is especially evident by observing dicer-like1 mutants, in which alterations are mainly at the level of embryo apical-basal-radial symmetry (Lang et al., 1994; Ray et al., 1996; Schauer et al., 2002).

During the process of seed maturity miRNAs also affect seed size. During gametophyte and early seed development, for example, miR172 targets several APETALA2-like transcription factors, thus controlling seed size and yield; ap2 loss-of-function causes an increase of seed weight (Jofuku et al., 2005; Tang et al., 2012). The miR172-AP2 interaction is conserved between Arabidopsis and maize (Wang et al., 2005).
Others miRNAs affecting seed size belong to two families, miR159 and miR319 (Palatnik et al., 2007; Li et al., 2011). miR159ab double mutant manifests a reduced seed size and seed shape alterations (Allen et al., 2007). miR319 has a central role in coordinating multiple miRNAs and is strictly connected to phytohormone regulation (Luo et al., 2011). This last seems to be an upstream regulator that targets several TCP transcription factors, which in turn activate the hormonal machinery through the recruitment of other miRNAs (Palatnik et al., 2003; Luo et al., 2011). The function of miR319 seems to be conserved also in maize where, in addition, this specific miRNA together with miR171 target genes that participate in secondary pathways of auxin and GA signaling transduction, thus affecting embryo differentiation (Zhang et al., 2009a; Kang et al., 2012; Shen et al., 2013).

Regarding the control exerted by miRNAs on phytohormones, it has been shown in Arabidopsis that auxin metabolism is controlled by at least four conserved miRNA families (miR160, miR167, miR390, and miR393), which mainly exert control by regulating ARF proteins (i.e., ARF6, ARF8, ARF10, ARF16, and 17) (Rhoades et al., 2002; Mallory et al., 2005; Marin et al., 2010; Windels and Vazquez, 2011; Kinoshita et al., 2012).

It has been observed that miRNAs in some cases also participate in the hormones cross-talk. For instance, it was reported that auxin and ABA signal transduction pathways are targets of differentially expressed miRNAs (Reyes and Chua, 2007). It was shown that miR159 and 160 affect the process of germination by regulating ABA sensitivity. Interestingly, miR160 is implicated in the regulation of auxin metabolism (Rhoades et al., 2002; Mallory et al., 2005); the mutants expressing a miR160-resistant form of ARF10 are hypersensitive to ABA (Liu et al., 2007a), therefore suggesting a point of cross-talk between $\mathrm{ABA}$ and auxin in imbibed seeds.

A deep sequencing approach has been used to identify seed specific miRNAs in maize (Zhang et al., 2006, 2009a; Wang et al., 2011; Kang et al., 2012). Most miR167 and miR319 families were found enriched in seeds rather than leaves (Kang et al., 2012). Target prediction of maize miRNAs found that miR167, as in Arabidopsis, targets ARFs (Zhang et al., 2009a). The conservation of both targets and miRNA in Arabidopsis and maize suggests conserved mechanisms of regulation in Monocots and Eudicots.

Another important example of conservation was recently reported in a study of miRNA regulation during the early development of barley grains. In this case, it was suggested that the miRNAs contribute to the control of the development of cereal grain particularly regulating phytohormone response pathways (Curaba et al., 2012). Specifically, the regulation of TIR1 and potentially three ARFs by the miR393 and miR167 families resulted conserved.

The more recent knowledge on miRNAs and their molecular connections and involvement in multiple hormonal responses and crosstalk, with patterning genes in specific developmental processes and also in seed development is discussed in detail in other excellent reviews (Nonogaki, 2010; Rubio-Somoza and Weigel, 2011; Curaba et al., 2014). 


\section{CONCLUDING REMARKS}

Spermatophytes have evolved seeds to ensure spreading and survival. Seed development and the inherent establishment of the final seed size is a multi-step process controlled by a complex network. Besides being a valuable model for basic research, it is also an important and interesting trait for farmers and the related industries, as seeds represent the basis for the food, feed and bio-based economy. However, despite the enormous advance on the study of the mechanisms controlling seed size, there are still open questions to answer. The general interest of the industry nowadays, apart from increasing production, is to modify the compounds accumulated in the seeds in order to improve their quality. With this perspective in mind, in these last years, many researchers have focused their attention on comparative studies between species, and the translation of information from model plants to crops. In this review we have summarized the known genes and elements involved in the process of seed development, particularly focusing on the auxin hormonal pathway, and underlining the concept that the proper distribution, transduction and coordination of all the hormonal signals is essential for seed development.

The early stages of the seed developmental program are very similar in Eudicots and Monocots. Nevertheless, remarkable differences have been described in the stage of seed maturation: while in Monocots the endosperm persists until maturation, being the compartment of nutrient storage for the embryo, in Eudicots it is gradually replaced by the embryo until being reduced to a single cell layer (Figure 1).

The initial genetic studies on seed biology aimed the identification and characterization of genes involved in fundamental processes associated with embryogenesis and seed development, based mainly on the characterization of mutants, misexpression experiments and the use of marker lines. Most of the genes identified showed relationship with phytohormones (Table 1). The knowledge of the pathways and events regulated by each hormone leads to the interesting possibility of specific hormones/hormone inhibitors being applied to the crops at specific moments in their development, in order to obtain the desired results in agricultural production.

Phytohormones are among the most relevant signals involved in the communication between seed structures. The communication among the three compartments of the seed (seed coat, endosperm and embryo) has been revealed to have a key role for the correct seed formation. In fact, failure in this communication can cause alteration in seed size, defective embryos and future seedlings and, in extreme cases, seed abortion. The characterization of mutants affecting hormonal signaling constitutes an interesting opportunity to describe relationships, relevance and mechanisms by which the signals are exchanged between seed compartments.

The difficulty in studying the role of genes whose mutations cause lethal phenotype in embryo/seed has recently been overcome with modern molecular biology techniques and by the use of -omics approaches. As mentioned in this review Lu et al. (2013), through the massive study of gene expression by RNA-sequencing, contributed to the identification of genes differentially expressed between embryo and endosperm, proposing interesting regulatory networks between the two compartments, in maize.

Several comparative studies between species are allowing the identification of the conserved and divergent elements acting in the regulatory mechanisms governing seed development. As shown in this review most of the crosstalk involving the factors that affect seed development (hormones, epigenetics and sugars) are conserved between maize and Arabidopsis (Figure 3). In addition, the identification and characterization of orthologous genes will permit the description of unknown genes function, and the definition of patterns of regulation that would otherwise be difficult to describe. For instance, the recent study by Chen et al. (2014) highlighted the different patterns of auxin and cytokinin accumulation during embryogenesis in the two model species Arabidopsis and maize. While in Arabidopsis the involvement of IAA in embryo development immediately after fertilization is clear, in maize this hormone is not detected in the embryo, but in the endosperm, during early embryogenesis. This result indicates the presence of a phase shift in the level of IAA accumulation during the early stages of embryo development when comparing the two species. Nevertheless, later in the development, the same pattern of hormone accumulation is observed at both scutellum (maize) and at the emerging cotyledon tips (Arabidopsis). The polar transport and the consequent IAA flux, which is essential in establishing the apical-basis pattern of the embryo, are conserved in both species as well. However, in maize after the differentiation of embryo meristems, auxin polar transport is also essential for the regular differentiation of both the leaf primordia at the SAM and the seminal root at the root apical meristem.

Similarly to auxin, cytokinin response is delayed in maize with respect to Arabidopsis. However, the antagonistic effect of auxin and cytokinins during embryogenesis is again conserved in these two species. The existence of a functional convergence in seed development between Arabidopsis and maize was moreover deduced by observing the phenotype of the Arabidopsis triple receptor kinase mutant $a h k 2 / a h k 3 / a h k 4$ and the effect of $Z m H K s$ overexpression in Arabidopsis transgenic lines. The seeds showed an increased size with respect to the wild type in the triple mutant while a reduction in size in the overexpressing lines.

At the later stages of seed development, ABA and IAA seem to co-regulate the expression of many genes involved in starch biosynthesis in maize endosperm and the accumulation of nourishing proteins in the arabidopsis cotyledons. This evidence underlines the importance of auxin during all the stages of seed development, from embryogenesis to maturation (Figure 1).

Although some of the factors controlling the seed development process have been identified, many are still unknown. For example, to date, there is no information available about the role of brassinosteroids in maize seed development.

The arduousness of these studies in maize is not only linked to methodology-limitation, but also mainly attributable to genomic complexities. In cereal crops, the high level of gene duplication with respect to Arabidopsis hinders the identification of orthologs, or the simple comparison of gene function. In Monocots several cases of sub-functionalization were reported. In maize, for example, it was shown that the PIN gene has been subjected to events of duplication that generated the four ZmPIN1a-d 
genes with different levels of tissue-specific expression. It has been suggested that these four genes could have gained new functions assembling the specific roles of AtPIN3, AtPIN4, and AtPIN7, which have still not been identified in the maize genome. Despite the problems concerning the study of crops with respect to the Eudicot model plants, specific areas of research are improving in Monocots. One of these is the characterization of the process of genome imprinting. This study is more advanced in maize than in Arabidopsis, due to the bigger seed size, the persistence of the endosperm and the straightforward physical separation of the seed structures.

Imprinting is fundamental for both embryo and endosperm differentiation during seed development, which interestingly is the sole plant developmental phase characterized by maternal dependency. The study of the dynamic of the imprinted genes during early and late stages of development, and their cross-talk with hormones will shed light on both the biological significance of this mechanism of gene expression regulation, and the connection between epigenetic mechanisms and hormonal control during seed development and maturation. The identification of miRNAs differentially expressed in the seed and their corresponding targets has established a new complicated link between miRNAs dynamics and the traditional role of hormones in seed development. However, the study of conservation of both miRNAs and target gene expression between different species during seed development still needs further investigations.

The use of the present and new marker lines and mutants, as well as the technical advances on transcriptomics, proteomics, genomics and metabolomics, will greatly contribute to the understanding of the environmental, hormonal, genetic, and epigenetic mechanisms and cross-talks that control seed production and development, and to establish parallelisms between Monocots and Eudicots in the near future.

\section{ACKNOWLEDGMENTS}

The authors are grateful to Dr. S. Masiero, M. Abbas, and A. Garside for revising the manuscript and for critical discussion. We would like to apologize with all our colleagues because for space constraints their work could not be discussed in this review. Antonella Locascio, Irma Roig-Villanova, and Jamila Bernardi were funded by the Ministry for Education and University, Italy (FIRB grant no. RBFR08UG7).

\section{REFERENCES}

Abel, S., and Theologis, A. (1996). Early genes and auxin action. Plant Physiol. 111, 9-17. doi: 10.1104/pp.111.1.9

Allen, R. S., Li, J., Stahle, M. I., Dubroue, A., Gubler, F., and Millar, A. A. (2007). Genetic analysis reveals functional redundancy and the major target genes of the Arabidopsis miR159 family. Proc. Natl. Acad. Sci. U.S.A. 104, 16371-16376. doi: 10.1073/pnas.0707653104

Bartel, D. P. (2004). MicroRNAs: genomics, biogenesis, mechanism, and function. Cell 116, 281-297. doi: 10.1016/S0092-8674(04)00045-5

Bate, N. J., Niu, X., Wang, Y., Reimann, K. S., and Helentjaris, T. G. (2004). An invertase inhibitor from maize localizes to the embryo surrounding region during early kernel development. Plant Physiol. 134, 246-254. doi: $10.1104 /$ pp. 103.027466

Baud, S., Wuilleme, S., Lemoine, R., Kronenberger, J., Caboche, M., Lepiniec, L., et al. (2005). The AtSUC5 sucrose transporter specifically expressed in the endosperm is involved in early seed development in Arabidopsis. Plant J. 43, 824-836. doi: 10.1111/j.1365-313X.2005.02496.x
Bauer, M. J., and Fischer, R. L. (2011). Genome demethylation and imprinting in the endosperm. Curr. Opin. Plant Biol. 14, 162-167. doi: 10.1016/j.pbi.2011.02.006

Bäumlein, H., Miséra, S., Luerßen, H., Kölle, K., Horstmann, C., Wobus, U., et al. (1994). The FUS3 gene of Arabidopsis thaliana is a regulator of gene expression during late embryogenesis. Plant J. 6, 379-387. doi: 10.1046/j.1365313X.1994.06030379.x

Becraft, P. W., and Asuncion-Crabb, Y. (2000). Positional cues specify and maintain aleurone cell fate in maize endosperm development. Development 127, 4039-4048.

Becraft, P. W., Stinard, P. S., and McCarty, D. R. (1996). CRINKLY4: a TNFRlike receptor kinase involved in maize epidermal differentiation. Science 273, 1406-1409. doi: 10.1126/science.273.5280.1406

Becraft, P. W., and Yi, G. (2011). Regulation of aleurone development in cereal grains. J. Exp. Bot. 62, 1669-1675. doi: 10.1093/jxb/erq372

Bemer, M., Wolters-Arts, M., Grossniklaus, U., and Angenent, G. C. (2008). The MADS domain protein DIANA acts together with AGAMOUS-LIKE80 to specify the central cell in Arabidopsis ovules. Plant Cell 20, 2088-2101. doi: $10.1105 /$ tpc. 108.058958

Bennett, M. J., Marchant, A., Green, H. G., May, S. T., Ward, S. P., Millner, P. A., et al. (1996). Arabidopsis AUX1 gene: a permease-like regulator of root gravitropism. Science 273, 948-950. doi: 10.1126/science.273.52 77.948

Berger, F. (2003). Endosperm: the crossroad of seed development. Curr. Opin. Plant Biol. 6, 42-50. doi: 10.1016/S1369526602000043

Berger, F., Grini, P. E., and Schnittger, A. (2006). Endosperm: an integrator of seed growth and development. Curr. Opin. Plant Biol. 9, 664-670. doi: 10.1016/j.pbi.2006.09.015

Berleth, T., and Jurgens, G. (1993). The role of the monopteros gene in organising the basal body region of the Arabidopsis embryo. Development 118, 575-587. doi: 10.1016/0168-9525(93)90246-E

Bernardi, J., Lanubile, A., Li, Q. B., Kumar, D., Kladnik, A., Cook, S. D., et al. (2012). Impaired auxin biosynthesis in the defective endosperm 18 mutant is due to mutational loss of expression in the $\mathrm{ZmYucl}$ gene encoding endosperm-specific YUCCA1 protein in maize. Plant Physiol. 160, 1318-1328. doi: $10.1104 /$ pp.112.204743

Bethke, P. C., Hwang, Y. S., Zhu, T., and Jones, R. L. (2006). Global patterns of gene expression in the aleurone of wild-type and dwarf1 mutant rice. Plant Physiol. 140, 484-498. doi: 10.1104/pp.105.074435

Bethke, P. C., Libourel, I. G., Aoyama, N., Chung, Y. Y., Still, D. W., and Jones, R. L. (2007). The Arabidopsis aleurone layer responds to nitric oxide, gibberellin, and abscisic acid and is sufficient and necessary for seed dormancy. Plant Physiol. 143, 1173-1188. doi: 10.1104/pp.106.093435

Bishopp, A., Benkova, E., and Helariutta, Y. (2011). Sending mixed messages: auxin-cytokinin crosstalk in roots. Curr. Opin. Plant Biol. 14, 10-16. doi: 10.1016/j.pbi.2010.08.014

Bossi, F., Cordoba, E., Dupre, P., Mendoza, M. S., Roman, C. S., and Leon, P. (2009). The Arabidopsis ABA-INSENSITIVE (ABI) 4 factor acts as a central transcription activator of the expression of its own gene, and for the induction of ABI5 and SBE2.2 genes during sugar signaling. Plant J. 59, 359-374. doi: 10.1111/j.1365-313X.2009.03877.x

Brown, R., Lemmon, B., and Olsen, O.-A. (1996a). Development of the endosperm in rice (Oryza sativa L.): cellularization. J. Plant Res. 109, 301-313. doi: 10.1007/BF02344477

Brown, R. C., Lemmon, B. E., and Olsen, O. A. (1996b). Polarization predicts the pattern of cellularization in cereal endosperm. Protoplasma 192, 168-177. doi: 10.1007/BF01273889

Brugiere, N., Humbert, S., Rizzo, N., Bohn, J., and Habben, J. E. (2008). A member of the maize isopentenyl transferase gene family, Zea mays isopentenyl transferase 2 (ZmIPT2), encodes a cytokinin biosynthetic enzyme expressed during kernel development. Cytokinin biosynthesis in maize. Plant Mol. Biol. 67, 215-229. doi: 10.1007/s11103-008-9312-x

Brugiere, N., Jiao, S., Hantke, S., Zinselmeier, C., Roessler, J. A., Niu, X., et al. (2003). Cytokinin oxidase gene expression in maize is localized to the vasculature, and is induced by cytokinins, abscisic acid, and abiotic stress. Plant Physiol. 132, 1228-1240. doi: 10.1104/pp.102.017707

Chaudhury, A. M., and Berger, F. (2001). Maternal control of seed development. Semin. Cell. Dev. Biol. 12, 381-386. doi: 10.1006/scdb. 2001.0267 
Chen, J., Huang, B., Li, Y., Du, H., Gu, Y., Liu, H., et al. (2011). Synergistic influence of sucrose and abscisic acid on the genes involved in starch synthesis in maize endosperm. Carbohydr. Res. 346, 1684-1691. doi: 10.1016/j.carres.2011.05.003

Chen, J., Lausser, A., and Dresselhaus, T. (2014). Hormonal responses during early embryogenesis in maize. Biochem. Soc. Trans. 42, 325-331. doi: 10.1042/BST20130260

Cheng, Y., Dai, X., and Zhao, Y. (2006). Auxin biosynthesis by the YUCCA flavin monooxygenases controls the formation of floral organs and vascular tissues in Arabidopsis. Genes Dev. 20, 1790-1799. doi: 10.1101/gad.1415106

Cheng, Y., Dai, X., and Zhao, Y. (2007). Auxin synthesized by the YUCCA flavin monooxygenases is essential for embryogenesis and leaf formation in Arabidopsis. Plant Cell 19, 2430-2439. doi: 10.1105/tpc.107.053009

Choe, S., Tanaka, A., Noguchi, T., Fujioka, S., Takatsuto, S., Ross, A. S., et al. (2000). Lesions in the sterol delta reductase gene of Arabidopsis cause dwarfism due to a block in brassinosteroid biosynthesis. Plant J. 21, 431-443. doi: 10.1046/j.1365313x.2000.00693.x

Choi, Y., Gehring, M., Johnson, L., Hannon, M., Harada, J. J., Goldberg, R. B., et al. (2002). DEMETER, a DNA glycosylase domain protein, is required for endosperm gene imprinting and seed viability in arabidopsis. Cell 110, 33-42. doi: 10.1016/S0092-8674(02)00807-3

Chory, J., Nagpal, P., and Peto, C. A. (1991). Phenotypic and genetic analysis of $\operatorname{det} 2$, a new mutant that affects light-regulated seedling development in Arabidopsis. Plant Cell 3, 445-459. doi: 10.1105/tpc.3.5.445

Chourey, P. S., Jain, M., Li, Q. B., and Carlson, S. J. (2006). Genetic control of cell wall invertases in developing endosperm of maize. Planta 223, 159-167. doi: 10.1007/s00425-005-0039-5

Chourey, P. S., Li, Q. B., and Kumar, D. (2010). Sugar-hormone cross-talk in seed development: two redundant pathways of IAA biosynthesis are regulated differentially in the invertase-deficient miniaturel $(\mathrm{mnl})$ seed mutant in maize. Mol. Plant 3, 1026-1036. doi: 10.1093/mp/ssq057

Costa, L. M., Yuan, J., Rouster, J., Paul, W., Dickinson, H., and Gutierrez-Marcos, J. F. (2012). Maternal control of nutrient allocation in plant seeds by genomic imprinting. Curr. Biol. 22, 160-165. doi: 10.1016/j.cub.2011.11.059

Curaba, J., Singh, M. B., and Bhalla, P. L. (2014). miRNAs in the crosstalk between phytohormone signalling pathways. J. Exp. Bot. 65, 1425-1438. doi: 10.1093/jxb/eru002

Curaba, J., Spriggs, A., Taylor, J., Li, Z., and Helliwell, C. (2012). miRNA regulation in the early development of barley seed. BMC Plant Biol. 12:120. doi: 10.1186/1471-2229-12-120

Day, R. C., Herridge, R. P., Ambrose, B. A., and Macknight, R. C. (2008) Transcriptome analysis of proliferating Arabidopsis endosperm reveals biological implications for the control of syncytial division, cytokinin signaling, and gene expression regulation. Plant Physiol. 148, 1964-1984. doi: 10.1104/pp.108.128108

Dharmasiri, N., Dharmasiri, S., Weijers, D., Lechner, E., Yamada, M., Hobbie, L., et al. (2005). Plant development is regulated by a family of auxin receptor $\mathrm{F}$ box proteins. Dev. Cell 9, 109-119. doi: 10.1016/j.devcel.2005.05.014

Dietrich, K. M. Jr., Blevins, D. G., Reinbott, T. M., and Morris, R. O. (1995). Changes in CKs and CK oxidase activity in developing maize kernels and the effects of exogenous CK on kernel development. Plant Physiol. Biochem. 33, 327-336. doi: 10.1016/j.plaphy.2012.12.010

Dorcey, E., Urbez, C., Blazquez, M. A., Carbonell, J., and Perez-Amador, M. A. (2009). Fertilization-dependent auxin response in ovules triggers fruit development through the modulation of gibberellin metabolism in Arabidopsis. Plant J. 58, 318-332. doi: 10.1111/j.1365-313X.2008.03781.x

Drews, G. N., Lee, D., and Christensen, C. A. (1998). Genetic analysis of female gametophyte development and function. Plant Cell 10, 5-17. doi: 10.1105/tpc.10.1.5

Fatihi, A., Zbierzak, A. M., and Dormann, P. (2013). Alterations in seed development gene expression affect size and oil content of Arabidopsis seeds. Plant Physiol. 163, 973-985. doi: 10.1104/pp.113.226761

Feil, R., and Berger, F. (2007). Convergent evolution of genomic imprinting in plants and mammals. Trends Genet. 23, 192-199. doi: 10.1016/j.tig.2007.02.004

Forestan, C., Farinati, S., and Varotto, S. (2012). The maize PIN gene family of auxin transporters. Front. Plant Sci. 3:16. doi: 10.3389/fpls.2012.00016

Forestan, C., Meda, S., and Varotto, S. (2010). ZmPIN1-mediated auxin transport is related to cellular differentiation during maize embryogenesis and endosperm development. Plant Physiol. 152, 1373-1390. doi: 10.1104/pp.109.150193
Forestan, C., and Varotto, S. (2010). PIN1 auxin efflux carriers localization studies in Zea mays. Plant Signal Behav. 5, 436-439. doi: 10.4161/psb.5.4.11339

Forestan, C., and Varotto, S. (2012). The role of PIN auxin efflux carriers in polar auxin transport and accumulation and their effect on shaping maize development. Mol. Plant 5, 787-798. doi: 10.1093/mp/ssr103

Friml, J., Vieten, A., Sauer, M., Weijers, D., Schwarz, H., Hamann, T., et al. (2003). Efflux-dependent auxin gradients establish the apical-basal axis of Arabidopsis. Nature 426, 147-153. doi: 10.1038/nature02085

Gallavotti, A., Barazesh, S., Malcomber, S., Hall, D., Jackson, D., Schmidt, R. J., et al. (2008). Sparse inflorescencel encodes a monocot-specific YUCCA-like gene required for vegetative and reproductive development in maize. Proc. Natl. Acad. Sci. U.S.A. 105, 15196-15201. doi: 10.1073/pnas.0805596105

Garcia, D., Fitz Gerald, J. N., and Berger, F. (2005). Maternal control of integument cell elongation and zygotic control of endosperm growth are coordinated to determine seed size in Arabidopsis. Plant Cell 17, 52-60. doi: $10.1105 /$ tpc. 104.027136

Garcia, D., Saingery, V., Chambrier, P., Mayer, U., Jurgens, G., and Berger, F. (2003). Arabidopsis haiku mutants reveal new controls of seed size by endosperm. Plant Physiol. 131, 1661-1670. doi: 10.1104/pp.102.018762

Gazzarrini, S., Tsuchiya, Y., Lumba, S., Okamoto, M., and McCourt, P. (2004). The transcription factor FUSCA3 controls developmental timing in Arabidopsis through the hormones gibberellin and abscisic acid. Dev. Cell 7, 373-385. doi: 10.1016/j.devcel.2004.06.017

Gehring, M., Huh, J. H., Hsieh, T. F., Penterman, J., Choi, Y., Harada, J. J., et al. (2006). DEMETER DNA glycosylase establishes MEDEA polycomb gene self-imprinting by allele-specific demethylation. Cell 124, 495-506. doi: 10.1016/j.cell.2005.12.034

Gehring, M., Missirian, V., and Henikoff, S. (2011). Genomic analysis of parent-oforigin allelic expression in Arabidopsis thaliana seeds. PLOS ONE 6:e23687. doi: 10.1371/journal.pone.0023687

Geisler-Lee, J., and Gallie, D. R. (2005). Aleurone cell identity is suppressed following connation in maize kernels. Plant Physiol. 139, 204-212. doi: 10.1104/pp.105.064295

Goldberg, R. B., Barker, S. J., and Perez-Grau, L. (1989). Regulation of gene expression during plant embryogenesis. Cell 56, 149-160. doi: 10.1016/00928674(89)90888-X

Goldberg, R. B., De Paiva, G., and Yadegari, R. (1994). Plant embryogenesis: zygote to seed. Science 266, 605-614. doi: 10.1126/science.266.5185.605

Grennan, A. K. (2008). Arabidopsis MicroRNAs. Plant Physiol. 146, 3-4. doi: 10.1104/pp.104.900244

Grossniklaus, U., Vielle-Calzada, J. P., Hoeppner, M. A., and Gagliano, W. B. (1998). Maternal control of embryogenesis by MEDEA, a polycomb group gene in Arabidopsis. Science 280, 446-450. doi: 10.1126/science.280.5362.446

Gruis, D. F., Guo, H., Selinger, D., Tian, Q., and Olsen, O. A. (2006). Surface position, not signaling from surrounding maternal tissues, specifies aleurone epidermal cell fate in maize. Plant Physiol. 141, 898-909. doi: 10.1104/pp.106.080945

Guilfoyle, T. J., and Hagen, G. (2007). Auxin response factors. Curr. Opin. Plant Biol. 10, 453-460. doi: 10.1016/j.pbi.2007.08.014

Gutierrez, R., Quiroz-Figueroa, F., and Vazquez-Ramos, J. M. (2005). Maize cyclin D2 expression, associated kinase activity and effect of phytohormones during germination. Plant Cell Physiol. 46, 166-173. doi: 10.1093/pcp/pci007

Gutierrez-Marcos, J. F., Costa, L. M., and Evans, M. M. (2006). Maternal gametophytic baseless 1 is required for development of the central cell and early endosperm patterning in maize (Zea mays). Genetics 174, 317-329. doi: 10.1534/genetics.106.059709

Hamann, T., Benkova, E., Baurle, I., Kientz, M., and Jurgens, G. (2002). The Arabidopsis BODENLOS gene encodes an auxin response protein inhibiting MONOPTEROS-mediated embryo patterning. Genes Dev. 16, 1610-1615. doi: $10.1101 / \mathrm{gad} .229402$

Hardtke, C. S., and Berleth, T. (1998). The Arabidopsis gene MONOPTEROS encodes a transcription factor mediating embryo axis formation and vascular development. EMBO J. 17, 1405-1411. doi: 10.1093/emboj/17.5.1405

Hartig, K., and Beck, E. (2006). Crosstalk between auxin, cytokinins, and sugars in the plant cell cycle. Plant Biol. (Stuttg.) 8, 389-396. doi: 10.1055/s-2006923797

Hartwig, T., Chuck, G. S., Fujioka, S., Klempien, A., Weizbauer, R., Potluri, D. P., et al. (2011). Brassinosteroid control of sex determination in maize. Proc. Natl. Acad. Sci. U.S.A. 108, 19814-19819. doi: 10.1073/pnas.1108359108 
Hennig, L., and Derkacheva, M. (2009). Diversity of Polycomb group complexes in plants: same rules, different players? Trends Genet. 25, 414-423. doi: 10.1016/j.tig.2009.07.002

Holdsworth, M. J., Bentsink, L., and Soppe, W. J. (2008). Molecular networks regulating Arabidopsis seed maturation, after-ripening, dormancy and germination. New Phytol. 179, 33-54. doi: 10.1111/j.1469-8137.2008.02437.x

Hong, Z., Ueguchi-Tanaka, M., Fujioka, S., Takatsuto, S., Yoshida, S., Hasegawa, Y., et al. (2005). The Rice brassinosteroid-deficient dwarf2 mutant, defective in the rice homolog of Arabidopsis DIMINUTO/DWARF1, is rescued by the endogenously accumulated alternative bioactive brassinosteroid, dolichosterone. Plant Cell 17, 2243-2254. doi: 10.1105/tpc.105.030973

Hsieh, T. F., Ibarra, C. A., Silva, P., Zemach, A., Eshed-Williams, L., Fischer, R. L., et al. (2009). Genome-wide demethylation of Arabidopsis endosperm. Science 324, 1451-1454. doi: 10.1126/science.1172417

Hsieh, T. F., Shin, J., Uzawa, R., Silva, P., Cohen, S., Bauer, M. J., et al. (2011). Regulation of imprinted gene expression in Arabidopsis endosperm. Proc. Natl. Acad. Sci. U.S.A. 108, 1755-1762. doi: 10.1073/pnas.1019273108

Hu, Y. F., Li, Y. P., Zhang, J., Liu, H., Tian, M., and Huang, Y. (2012). Binding of ABI4 to a CACCG motif mediates the ABA-induced expression of the ZmSSI gene in maize (Zea mays L.) endosperm. J. Exp. Bot. 63, 5979-5989. doi: $10.1093 /$ jxb/ers 246

Hwang, I., Sheen, J., and Muller, B. (2012). Cytokinin signaling networks. Annu. Rev. Plant Biol. 63, 353-380. doi: 10.1146/annurev-arplant-042811-105503

Ibarra, C. A., Feng, X., Schoft, V. K., Hsieh, T. F., Uzawa, R., Rodrigues, J. A., et al. (2012). Active DNA demethylation in plant companion cells reinforces transposon methylation in gametes. Science 337, 1360-1364. doi: 10.1126/science. 1224839

Jahnke, S., and Scholten, S. (2009). Epigenetic resetting of a gene imprinted in plant embryos. Curr. Biol. 19, 1677-1681. doi: 10.1016/j.cub.2009.08.053

Jenik, P. D., and Barton, M. K. (2005). Surge and destroy: the role of auxin in plant embryogenesis. Development 132, 3577-3585. doi: 10.1242/dev.01952

Jiang, W. B., Huang, H. Y., Hu, Y. W., Zhu, S. W., Wang, Z. Y., and Lin, W. H. (2013). Brassinosteroid regulates seed size and shape in Arabidopsis. Plant Physiol. 162, 1965-1977. doi: 10.1104/pp.113.217703

Jiang, W. B., and Lin, W. H. (2013). Brassinosteroid functions in Arabidopsis seed development. Plant Signal. Behav. 8:e25928. doi: 10.4161/psb.25928

Jofuku, K. D., Omidyar, P. K., Gee, Z., and Okamuro, J. K. (2005). Control of seed mass and seed yield by the floral homeotic gene APETALA2. Proc. Natl. Acad. Sci. U.S.A. 102, 3117-3122. doi: 10.1073/pnas.0409893102

Jones, A. M. (1990). Location of transported auxin in etiolated maize shoots using 5-azidoindole-3-acetic Acid. Plant Physiol. 93, 1154-1161. doi: 10.1104/pp. 93.3.1154

Kang, B. H., Xiong, Y., Williams, D. S., Pozueta-Romero, D., and Chourey, P. S. (2009). Miniaturel-encoded cell wall invertase is essential for assembly and function of wall-in-growth in the maize endosperm transfer cell. Plant Physiol. 151, 1366-1376. doi: 10.1104/pp.109.142331

Kang, M., Zhao, Q., Zhu, D., and Yu, J. (2012). Characterization of microRNAs expression during maize seed development. BMC Genomics 13:360. doi: 10.1186/1471-2164-13-360

Kang, X., and Ni, M. (2006). Arabidopsis SHORT HYPOCOTYL UNDER BLUE1 contains SPX and EXS domains and acts in cryptochrome signaling. Plant Cell 18, 921-934. doi: 10.1105/tpc.105.037879

Kanno, Y., Jikumaru, Y., Hanada, A., Nambara, E., Abrams, S. R., Kamiya, Y., et al. (2010). Comprehensive hormone profiling in developing Arabidopsis seeds: examination of the site of ABA biosynthesis, ABA transport and hormone interactions. Plant Cell Physiol. 51, 1988-2001. doi: 10.1093/pcp/pcq158

Karssen, C. M., Brinkhorst-Van Der Swan, D. L., Breekland, A. E., and Koornneef, M. (1983). Induction of dormancy during seed development by endogenous abscisic acid: studies on abscisic acid deficient genotypes of Arabidopsis thaliana (L.) Heynh. Planta 157, 158-165. doi: 10.1007/BF00393650

Kelley, D. R., Arreola, A., Gallagher, T. L., and Gasser, C. S. (2012). ETTIN (ARF3) physically interacts with KANADI proteins to form a functional complex essential for integument development and polarity determination in Arabidopsis. Development 139, 1105-1109. doi: 10.1242/dev.067918

Kepinski, S., and Leyser, O. (2005). The Arabidopsis F-box protein TIR1 is an auxin receptor. Nature 435, 446-451. doi: 10.1038/nature03542

Kim, J., Harter, K., and Theologis, A. (1997). Protein-protein interactions among the Aux/IAA proteins. Proc. Natl. Acad. Sci. U.S.A. 94, 11786-11791. doi: 10.1073/pnas.94.22.11786
Kinoshita, N., Wang, H., Kasahara, H., Liu, J., Macpherson, C., Machida, Y., et al. (2012). IAA-Ala Resistant3, an evolutionarily conserved target of miR167, mediates Arabidopsis root architecture changes during high osmotic stress. Plant Cell 24, 3590-3602. doi: 10.1105/tpc.112.097006

Koornneef, M., Jorna, M. L., Brinkhorst-Van Der Swan, D. L., and Karssen, C. M. (1982). The isolation of abscisic acid (ABA) deficient mutants by selection of induced revertants in non-germinating gibberellin sensitive lines of Arabidopsis thaliana (L.) heynh. Theor. Appl. Genet. 61, 385-393. doi: 10.1007/BF00272861

Lang, J. D., Ray, S., and Ray, A. (1994). sin 1, a mutation affecting female fertility in Arabidopsis, interacts with mod 1, its recessive modifier. Genetics 137, 1101-1110.

Law, J. A., and Jacobsen, S. E. (2010). Establishing, maintaining and modifying DNA methylation patterns in plants and animals. Nat. Rev. Genet. 11, 204-220. doi: $10.1038 / \mathrm{nrg} 2719$

Le Clere, S., Schmelz, E. A., and Chourey, P. S. (2010). Sugar levels regulate tryptophan-dependent auxin biosynthesis in developing maize kernels. Plant Physiol. 153, 306-318. doi: 10.1104/pp.110.155226

Leubner-Metzger, G. (2001). Brassinosteroids and gibberellins promote tobacco seed germination by distinct pathways. Planta 213, 758-763. doi: 10.1007/s004250100542

Li, J., and Nam, K. H. (2002). Regulation of brassinosteroid signaling by a GSK3/SHAGGY-like kinase. Science 295, 1299-1301. doi: 10.1126/science. 1065769

Li, J., Nam, K. H., Vafeados, D., and Chory, J. (2001). BIN2, a new brassinosteroid-insensitive locus in Arabidopsis. Plant Physiol. 127, 14-22. doi: 10.1104/pp.127.1.14

Li, J., Nie, X., Tan, J. L., and Berger, F. (2013). Integration of epigenetic and genetic controls of seed size by cytokinin in Arabidopsis. Proc. Natl. Acad. Sci. U.S.A. 110, 15479-15484. doi: 10.1073/pnas.1305175110

Li, Y., Li, C., Ding, G., and Jin, Y. (2011). Evolution of MIR159/319 microRNA genes and their post-transcriptional regulatory link to siRNA pathways. BMC Evol. Biol. 11:122. doi: 10.1186/1471-2148-11-122

Lid, S. E., Gruis, D., Jung, R., Lorentzen, J. A., Ananiev, E., Chamberlin, M., et al. (2002). The defective kernel 1 (dek1) gene required for aleurone cell development in the endosperm of maize grains encodes a membrane protein of the calpain gene superfamily. Proc. Natl. Acad. Sci. U.S.A. 99, 5460-5465. doi: 10.1073/pnas.042098799

Lid, S. E., Olsen, L., Nestestog, R., Aukerman, M., Brown, R. C., Lemmon, B. et al. (2005). Mutation in the Arabidopisis thaliana DEK1 calpain gene perturbs endosperm and embryo development while over-expression affects organ development globally. Planta 221, 339-351. doi: 10.1007/s00425-004-1448-6

Liu, P. P., Montgomery, T. A., Fahlgren, N., Kasschau, K. D., Nonogaki, H., and Carrington, J. C. (2007a). Repression of AUXIN RESPONSE FACTOR10 by microRNA160 is critical for seed germination and post-germination stages. Plant J. 52, 133-146. doi: 10.1111/j.1365-313X.2007.03218.x

Liu, T., Zhang, J., Wang, M., Wang, Z., Li, G., Qu, L., et al. (2007b). Expression and functional analysis of ZmDWF4, an ortholog of Arabidopsis DWF4 from maize (Zea mays L.). Plant Cell Rep. 26, 2091-2099. doi: 10.1007/s00299-007-0418-4

Liu, X., Zhang, H., Zhao, Y., Feng, Z., Li, Q., Yang, H. Q., et al. (2013). Auxin controls seed dormancy through stimulation of abscisic acid signaling by inducing ARF-mediated ABI3 activation in Arabidopsis. Proc. Natl. Acad. Sci. U.S.A. 110, 15485-15490. doi: 10.1073/pnas.1304651110

Liu, Y., Jiang, H., Chen, W., Qian, Y., Ma, Q., Cheng, B., et al. (2011). Genome-wide analysis of the auxin response factor (ARF) gene family in maize (Zea mays). Plant Growth Regul. 63, 225-234. doi: 10.1007/s10725-010-9519-0

Liu, Y., Ye, N., Liu, R., Chen, M., and Zhang, J. (2010). H2O2 mediates the regulation of ABA catabolism and GA biosynthesis in Arabidopsis seed dormancy and germination. J. Exp. Bot. 61, 2979-2990. doi: 10.1093/jxb/erq125

Lopato, S., Borisjuk, N., Langridge, P., and Hrmova, M. (2014). Endosperm transfer cell-specific genes and proteins: structure, function and applications in biotechnology. Front. Plant Sci. 5:64. doi: 10.3389/fpls.2014.00064

Lotan, T., Ohto, M., Yee, K. M., West, M. A., Lo, R., Kwong, R. W., et al. (1998). Arabidopsis LEAFY COTYLEDON1 is sufficient to induce embryo development in vegetative cells. Cell 93, 1195-1205. doi: 10.1016/S0092-8674(00) 81463-4

Lu, X., Chen, D., Shu, D., Zhang, Z., Wang, W., Klukas, C., et al. (2013). The differential transcription network between embryo and endosperm in the early developing maize seed. Plant Physiol. 162, 440-455. doi: 10.1104/pp.113. 214874 
Luo, M., Dennis, E. S., Berger, F., Peacock, W. J., and Chaudhury, A. (2005). MINISEED3 (MINI3), a WRKY family gene, and HAIKU2 (IKU2), a leucinerich repeat (LRR) KINASE gene, are regulators of seed size in Arabidopsis. Proc. Natl. Acad. Sci. U.S.A. 102, 17531-17536. doi: 10.1073/pnas.0508418102.

Luo, M., Taylor, J. M., Spriggs, A., Zhang, H., Wu, X., Russell, S., et al. (2011). A genome-wide survey of imprinted genes in rice seeds reveals imprinting primarily occurs in the endosperm. PLoS Genet. 7:e1002125. doi: 10.1371/journal.pgen. 1002125

Lur, H.-S., and Setter, T. L. (1993a). Endorsperm development of maize defective kernel (dek) mutants. Auxin and cytokinin levels. Ann. Bot. 72, 1-6. doi: 10.1006/anbo.1993.1074

Lur, H. S., and Setter, T. L. (1993b). Role of auxin in maize endosperm development (Timing of nuclear DNA endoreduplication, zein expression, and cytokinin). Plant Physiol. 103, 273-280. doi: 10.1104/pp.103.1.273

Maitz, M., Santandrea, G., Zhang, Z., Lal, S., Hannah, L. C., Salamini, F., et al. (2000). rgf1, a mutation reducing grain filling in maize through effects on basal endosperm and pedicel development. Plant J. 23, 29-42. doi: 10.1046/j.1365313x.2000.00747.x

Makarevitch, I., Thompson, A., Muehlbauer, G. J., and Springer, N. M. (2012). Brd1 gene in maize encodes a brassinosteroid C-6 oxidase. PLoS ONE 7:e30798. doi: 10.1371/journal.pone.0030798

Mallory, A. C., Bartel, D. P., and Bartel, B. (2005). MicroRNA-directed regulation of Arabidopsis AUXIN RESPONSE FACTOR17 is essential for proper development and modulates expression of early auxin response genes. Plant Cell 17, 1360-1375. doi: $10.1105 /$ tpc. 105.031716

Manzocchi, L. A., Daminati, M. G., Gentinetta, E., and Salamini, F. (1980). Viable defective endosperm mutants in maize. I. Kernel weight, protein fractions and zein subunits in mature endosperms. Maydica 25, 105-116.

Marin, E., Jouannet, V., Herz, A., Lokerse, A. S., Weijers, D., Vaucheret, H., et al. (2010). miR390, Arabidopsis TAS3 tasiRNAs, and their AUXIN RESPONSE FACTOR targets define an autoregulatory network quantitatively regulating lateral root growth. Plant Cell 22, 1104-1117. doi: 10.1105/tpc.109.072553

Martinez-Andujar, C., Pluskota, W. E., Bassel, G. W., Asahina, M., Pupel, P., Nguyen, T. T., et al. (2012). Mechanisms of hormonal regulation of endosperm cap-specific gene expression in tomato seeds. Plant J. 71, 575-586. doi: 10.1111/j.1365-313X.2012.05010.x

Mashiguchi, K., Tanaka, K., Sakai, T., Sugawara, S., Kawaide, H., Natsume, M., et al. (2011). The main auxin biosynthesis pathway in Arabidopsis. Proc. Natl. Acad. Sci. U.S.A. 108, 18512-18517. doi: 10.1073/pnas.1108434108

Meinke, D. W., Franzmann, L. H., Nickle, T. C., and Yeung, E. C. (1994). Leafy cotyledon mutants of Arabidopsis. Plant Cell 6, 1049-1064. doi: 10.1105/tpc.6.8.1049

Monke, G., Seifert, M., Keilwagen, J., Mohr, M., Grosse, I., Hahnel, U., et al. (2012). Toward the identification and regulation of the Arabidopsis thaliana ABI3 regulon. Nucleic Acids Res. 40, 8240-8254. doi: 10.1093/nar/gks594

Morinaka, Y., Sakamoto, T., Inukai, Y., Agetsuma, M., Kitano, H., Ashikari, M., et al. (2006). Morphological alteration caused by brassinosteroid insensitivity increases the biomass and grain production of rice. Plant Physiol. 141, 924-931. doi: 10.1104/pp.106.077081

Muller, B., and Sheen, J. (2008). Cytokinin and auxin interaction in root stemcell specification during early embryogenesis. Nature 453, 1094-1097. doi: 10.1038/nature06943

Nadeau, C. D., Ozga, J. A., Kurepin, L. V., Jin, A., Pharis, R. P., and Reinecke, D. M. (2011). Tissue-specific regulation of gibberellin biosynthesis in developing pea seeds. Plant Physiol. 156, 897-912. doi: 10.1104/pp.111.172577

Nawy, T., Lukowitz, W., and Bayer, M. (2008). Talk global, act localpatterning the Arabidopsis embryo. Curr. Opin. Plant Biol. 11, 28-33. doi: 10.1016/j.pbi.2007.10.007

Neuffer, M. G., and Sheridan, W. F. (1980). Defective kernel mutants of maize. I. Genetic and lethality studies. Genetics 95, 929-944.

Ni, D. A., Wang, L. J., Ding, C. H., and Xu, Z. H. (2001). Auxin distribution and transport during embryogenesis and seed germination of Arabidopsis. Cell Res. 11, 273-278. doi: 10.1038/sj.cr.7290096

Nodine, M. D., and Bartel, D. P. (2010). MicroRNAs prevent precocious gene expression and enable pattern formation during plant embryogenesis. Genes Dev. 24, 2678-2692. doi: 10.1101/gad.1986710

Nonogaki, H. (2010). MicroRNA gene regulation cascades during early stages of plant development. Plant Cell Physiol. 51, 1840-1846. doi: 10.1093/pcp/pcq154
Nowack, M. K., Ungru, A., Bjerkan, K. N., Grini, P. E., and Schnittger, A. (2010). Reproductive cross-talk: seed development in flowering plants. Biochem. Soc. Trans. 38, 604-612. doi: 10.1042/BST0380604

Ohto, M. A., Fischer, R. L., Goldberg, R. B., Nakamura, K., and Harada, J. J. (2005). Control of seed mass by APETALA2. Proc. Natl. Acad. Sci. U.S.A. 102, 3123-3128. doi: 10.1073/pnas.0409858102

Ohto, M. A., Floyd, S. K., Fischer, R. L., Goldberg, R. B., and Harada, J. J. (2009). Effects of APETALA2 on embryo, endosperm, and seed coat development determine seed size in Arabidopsis. Sex. Plant Reprod. 22, 277-289. doi: 10.1007/s00497-009-0116-1

Okushima, Y., Overvoorde, P. J., Arima, K., Alonso, J. M., Chan, A., Chang, C., et al. (2005). Functional genomic analysis of the AUXIN RESPONSE FACTOR gene family members in Arabidopsis thaliana: unique and overlapping functions of ARF7 and ARF19. Plant Cell 17, 444-463. doi: 10.1105/tpc.104.028316

Olsen, O. A. (2004). Nuclear endosperm development in cereals and Arabidopsis thaliana. Plant Cell 16(Suppl.), S214-S227. doi: 10.1105/tpc.017111

Orsi, C. H., and Tanksley, S. D. (2009). Natural variation in an ABC transporter gene associated with seed size evolution in tomato species. PLoS Genet. 5:e1000347. doi: 10.1371/journal.pgen.1000347

Palatnik, J. F., Allen, E., Wu, X., Schommer, C., Schwab, R., Carrington, J. C., et al. (2003). Control of leaf morphogenesis by microRNAs. Nature 425, 257-263. doi: 10.1038/nature01958

Palatnik, J. F., Wollmann, H., Schommer, C., Schwab, R., Boisbouvier, J., Rodriguez, R., et al. (2007). Sequence and expression differences underlie functional specialization of Arabidopsis microRNAs miR159 and miR319. Dev. Cell 13, 115-125. doi: 10.1016/j.devcel.2007.04.012

Parcy, F., and Giraudat, J. (1997). Interactions between the ABIl and the ectopically expressed ABI3 genes in controlling abscisic acid responses in Arabidopsis vegetative tissues. Plant J. 11, 693-702. doi: 10.1046/j.1365-313X1997.11040693.x

Pasini, L., Stile, M., Puja, E., Valsecchi, R., Francia, P., Carletti, G., et al. (2008). The integration of mutant loci affecting maize endosperm development in a dense genetic map using an AFLP-based procedure. Mol. Breed. 22, 527-541. doi: 10.1007/s11032-008-9196-0

Petrasek, J., Mravec, J., Bouchard, R., Blakeslee, J. J., Abas, M., Seifertova, D., et al. (2006). PIN proteins perform a rate-limiting function in cellular auxin efflux. Science 312, 914-918. doi: 10.1126/science.1123542

Phillips, K. A., Skirpan, A. L., Liu, X., Christensen, A., Slewinski, T. L., Hudson, C., et al. (2011). Vanishing tassel2 encodes a grass-specific tryptophan aminotransferase required for vegetative and reproductive development in maize. Plant Cell 23, 550-566. doi: 10.1105/tpc.110.075267

Pignocchi, C., Minns, G. E., Nesi, N., Koumproglou, R., Kitsios, G., Benning, C., et al. (2009). ENDOSPERM DEFECTIVE1 is a novel microtubule-associated protein essential for seed development in Arabidopsis. Plant Cell 21, 90-105. doi: 10.1105/tpc.108.061812

Portereiko, M. F., Lloyd, A., Steffen, J. G., Punwani, J. A., Otsuga, D., and Drews, G. N. (2006). AGL80 is required for central cell and endosperm development in Arabidopsis. Plant Cell 18, 1862-1872. doi: 10.1105/tpc.106.040824

Raissig, M. T., Baroux, C., and Grossniklaus, U. (2011). Regulation and flexibility of genomic imprinting during seed development. Plant Cell 23, 16-26. doi: 10.1105/tpc. 110.081018

Raissig, M. T., Bemer, M., Baroux, C., and Grossniklaus, U. (2013). Genomic imprinting in the Arabidopsis embryo is partly regulated by PRC2. PLoS Genet 9:e1003862. doi: 10.1371/journal.pgen.1003862

Rashotte, A. M., Mason, M. G., Hutchison, C. E., Ferreira, F. J., Schaller, G. E., and Kieber, J. J. (2006). A subset of Arabidopsis AP2 transcription factors mediates cytokinin responses in concert with a two-component pathway. Proc. Natl. Acad. Sci. U.S.A. 103, 11081-11085. doi: 10.1073/pnas.0602038103

Ray, A., Lang, J. D., Golden, T., and Ray, S. (1996). SHORT INTEGUMENT (SIN1), a gene required for ovule development in Arabidopsis, also controls flowering time. Development 122, 2631-2638.

Raz, V., Bergervoet, J. H., and Koornneef, M. (2001). Sequential steps for developmental arrest in Arabidopsis seeds. Development 128, 243-252.

Reik, W., and Walter, J. (2001). Genomic imprinting: parental influence on the genome. Nat. Rev. Genet. 2, 21-32. doi: 10.1038/35047554

Reinhart, B. J., Weinstein, E. G., Rhoades, M. W., Bartel, B., and Bartel, D. P. (2002). MicroRNAs in plants. Genes Dev. 16, 1616-1626. doi: 10.1101/gad.1004402

Reiser, L., and Fischer, R. L. (1993). The ovule and the embryo sac. Plant Cell 5, 1291-1301. doi: 10.1105/tpc.5.10.1291 
Reyes, F. C., Sun, B., Guo, H., Gruis, D. F., and Otegui, M. S. (2010). Agrobacterium tumefaciens-mediated transformation of maize endosperm as a tool to study endosperm cell biology. Plant Physiol. 153, 624-631. doi: $10.1104 /$ pp. 110.154930

Reyes, J. L., and Chua, N. H. (2007). ABA induction of miR159 controls transcript levels of two MYB factors during Arabidopsis seed germination. Plant J. 49, 592-606. doi: 10.1111/j.1365-313X.2006.02980.x

Rhoades, M. W., Reinhart, B. J., Lim, L. P., Burge, C. B., Bartel, B., and Bartel, D. P. (2002). Prediction of plant microRNA targets. Cell 110, 513-520. doi: 10.1016/S0092-8674(02)00863-2

Riefler, M., Novak, O., Strnad, M., and Schmulling, T. (2006). Arabidopsis cytokinin receptor mutants reveal functions in shoot growth, leaf senescence, seed size, germination, root development, and cytokinin metabolism. Plant Cell 18, 40-54. doi: 10.1105/tpc.105.037796

Rijavec, T., and Dermastia, M. (2010). Cytokinins and their function in developing seeds. Acta Chim. Slov. 57, 617-629.

Rijavec, T., Jain, M., Dermastia, M., and Chourey, P. S. (2011). Spatial and temporal profiles of cytokinin biosynthesis and accumulation in developing caryopses of maize. Ann. Bot. 107, 1235-1245. doi: 10.1093/aob/mcq247

Rijavec, T., Kovac, M., Kladnik, A., Chourey, P. S., and Dermastia, M. (2009). A comparative study on the role of cytokinins in caryopsis development in the maize miniaturel seed mutant and its wild type. J. Integr. Plant Biol. 51, 840-849. doi: 10.1111/j.1744-7909.2009.00863.x

Riou-Khamlichi, C., Huntley, R., Jacqmard, A., and Murray, J. A. (1999). Cytokinin activation of Arabidopsis cell division through a D-type cyclin. Science 283, 1541-1544. doi: 10.1126/science.283.5407.1541

Rodrigues, J. A., Ruan, R., Nishimura, T., Sharma, M. K., Sharma, R., Ronald, P. C., et al. (2013). Imprinted expression of genes and small RNA is associated with localized hypomethylation of the maternal genome in rice endosperm. Proc. Natl. Acad. Sci. U.S.A. 110, 7934-7939. doi: 10.1073/pnas.1306164110

Rook, F., Corke, F., Card, R., Munz, G., Smith, C., and Bevan, M. W. (2001). Impaired sucrose-induction mutants reveal the modulation of sugar-induced starch biosynthetic gene expression by abscisic acid signalling. Plant J. 26, 421-433. doi: 10.1046/j.1365-313X.2001.2641043.x

Ruan, Y. L., Jin, Y., Yang, Y. J., Li, G. J., and Boyer, J. S. (2010). Sugar input, metabolism, and signaling mediated by invertase: roles in development, yield potential, and response to drought and heat. Mol. Plant 3, 942-955. doi: $10.1093 / \mathrm{mp} / \mathrm{ssq} 044$

Rubio-Somoza, I., and Weigel, D. (2011). MicroRNA networks and developmental plasticity in plants. Trends Plant Sci. 16, 258-264. doi: 10.1016/j.tplants.2011.03.001

Sabelli, P. A., and Larkins, B. A. (2009). The development of endosperm in grasses. Plant Physiol. 149, 14-26. doi: 10.1104/pp.108.129437

Sairanen, I., Novak, O., Pencik, A., Ikeda, Y., Jones, B., Sandberg, G., et al. (2012). Soluble carbohydrates regulate auxin biosynthesis via PIF proteins in Arabidopsis. Plant Cell 24, 4907-4916. doi: 10.1105/tpc.112.104794

Salas Fernandez, M. G., Becraft, P. W., Yin, Y., and Lubberstedt, T. (2009). From dwarves to giants? Plant height manipulation for biomass yield. Trends Plant Sci. 14, 454-461. doi: 10.1016/j.tplants.2009.06.005

Santos-Mendoza, M., Dubreucq, B., Baud, S., Parcy, F., Caboche, M., and Lepiniec, L. (2008). Deciphering gene regulatory networks that control seed development and maturation in Arabidopsis. Plant J. 54, 608-620. doi: 10.1111/j.1365313X.2008.03461.x

Saoussem, H., Sadok, B., Habib, K., and Mayer, P. M. (2009). Fatty acid accumulation in the different fractions of the developing corn kernel. Food Chem. 117, 432-437. doi: 10.1016/j.foodchem.2009.04.038

Scanlon, M. J., Henderson, D. C., and Bernstein, B. (2002). SEMAPHORE1 functions during the regulation of ancestrally duplicated knox genes and polar auxin transport in maize. Development 129, 2663-2673.

Scanlon, M. J., Stinard, P. S., James, M. G., Myers, A. M., and Robertson, D. S. (1994). Genetic analysis of 63 mutations affecting maize kernel development isolated from Mutator stocks. Genetics 136, 281-294.

Schauer, S. E., Jacobsen, S. E., Meinke, D. W., and Ray, A. (2002). DICER-LIKE1: blind men and elephants in Arabidopsis development. Trends Plant Sci. 7, 487-491. doi: 10.1016/S1360-1385(02)02355-5

Schruff, M. C., Spielman, M., Tiwari, S., Adams, S., Fenby, N., and Scott, R. J. (2006). The AUXIN RESPONSE FACTOR 2 gene of Arabidopsis links auxin signalling, cell division, and the size of seeds and other organs. Development 133, 251-261. doi: 10.1242/dev.02194
Seefried, W. F., Willmann, M. R., Clausen, R. L., and Jenik, P. D. (2014). Global regulation of embryonic patterning in Arabidopsis by microRNAs. Plant Physiol. 165, 670-687. doi: 10.1104/pp.114.240846

Seiler, C., Harshavardhan, V. T., Rajesh, K., Reddy, P. S., Strickert, M., Rolletschek, H., et al. (2011). ABA biosynthesis and degradation contributing to ABA homeostasis during barley seed development under control and terminal drought-stress conditions. J. Exp. Bot. 62, 2615-2632. doi: 10.1093/jxb/ erq446

Sekhon, R. S., Hirsch, C. N., Childs, K. L., Breitzman, M. W., Kell, P., Duvick, S., et al. (2014). Phenotypic and transcriptional analysis of divergently selected maize populations reveals the role of developmental timing in seed size determination. Plant Physiol. 165, 658-669. doi: 10.1104/pp.114.235424

Seo, M., Hanada, A., Kuwahara, A., Endo, A., Okamoto, M., Yamauchi, Y., et al. (2006). Regulation of hormone metabolism in Arabidopsis seeds: phytochrome regulation of abscisic acid metabolism and abscisic acid regulation of gibberellin metabolism. Plant J. 48, 354-366. doi: 10.1111/j.1365-313X.2006.02881.x

Shen, Y., Jiang, Z., Lu, S., Lin, H., Gao, S., Peng, H., et al. (2013). Combined small RNA and degradome sequencing reveals microRNA regulation during immature maize embryo dedifferentiation. Biochem. Biophys. Res. Commun. 441, 425-430. doi: 10.1016/j.bbrc.2013.10.113

Sheridan, W. F., and Clark, J. K. (1987). Maize embryogeny: a promising experimental system. Trends Genet. 3, 3-6. doi: 10.1016/0168-9525(87)90153-3

Sheridan, W. F., and Neuffer, M. G. (1980). Defective kernel mutants of maize II Morphological and embryo culture studies. Genetics 95, 945-960.

Singh, D. P., Filardo, F. F., Storey, R., Jermakow, A. M., Yamaguchi, S., and Swain, S. M. (2010). Overexpression of a gibberellin inactivation gene alters seed development, KNOX gene expression, and plant development in Arabidopsis. Physiol. Plant. 138, 74-90. doi: 10.1111/j.1399-3054.2009.01289.x

Smehilova, M., Galuszka, P., Bilyeu, K. D., Jaworek, P., Kowalska, M., Sebela, M., et al. (2009). Subcellular localization and biochemical comparison of cytosolic and secreted cytokinin dehydrogenase enzymes from maize. J. Exp. Bot. 60, 2701-2712. doi: 10.1093/jxb/erp126

Sorensen, M. B., Mayer, U., Lukowitz, W., Robert, H., Chambrier, P., Jurgens, G. et al. (2002). Cellularisation in the endosperm of Arabidopsis thaliana is coupled to mitosis and shares multiple components with cytokinesis. Development 129, 5567-5576. doi: 10.1242/dev.00152

Sreenivasulu, N., and Wobus, U. (2013). Seed-development programs: a systems biology-based comparison between dicots and monocots. Annu. Rev. Plant Biol. 64, 189-217. doi: 10.1146/annurev-arplant-050312-120215

Stepanova, A. N., Yun, J., Robles, L. M., Novak, O., He, W., Guo, H., et al. (2011). The Arabidopsis YUCCA1 flavin monooxygenase functions in the indole-3pyruvic acid branch of auxin biosynthesis. Plant Cell 23, 3961-3973. doi: 10.1105/tpc.111.088047

Stone, S. L., Braybrook, S. A., Paula, S. L., Kwong, L. W., Meuser, J., Pelletier, J., et al. (2008). Arabidopsis LEAFY COTYLEDON2 induces maturation traits and auxin activity: implications for somatic embryogenesis. Proc. Natl. Acad. Sci. U.S.A. 105, 3151-3156. doi: 10.1073/pnas.0712364105

Sun, X., Shantharaj, D., Kang, X., and Ni, M. (2010). Transcriptional and hormonal signaling control of Arabidopsis seed development. Curr. Opin. Plant Biol. 13, 611-620. doi: 10.1016/j.pbi.2010.08.009

Takahashi, N., Nakazawa, M., Shibata, K., Yokota, T., Ishikawa, A., Suzuki, K. et al. (2005). shk1-D, a dwarf Arabidopsis mutant caused by activation of the CYP72C1 gene, has altered brassinosteroid levels. Plant J. 42, 13-22. doi: 10.1111/j.1365-313X.2005.02357.x

Tan, X., Calderon-Villalobos, L. I., Sharon, M., Zheng, C., Robinson, C. V., Estelle, M., et al. (2007). Mechanism of auxin perception by the TIR1 ubiquitin ligase. Nature 446, 640-645. doi: 10.1038/nature05731

Tanabe, S., Ashikari, M., Fujioka, S., Takatsuto, S., Yoshida, S., Yano, M., et al. (2005). A novel cytochrome P450 is implicated in brassinosteroid biosynthesis via the characterization of a rice dwarf mutant, dwarf11, with reduced seed length. Plant Cell 17, 776-790. doi: 10.1105/tpc.104.024950

Tanaka, H., Dhonukshe, P., Brewer, P. B., and Friml, J. (2006). Spatiotemporal asymmetric auxin distribution: a means to coordinate plant development. Cell Mol. Life Sci. 63, 2738-2754. doi: 10.1007/s00018-006-6116-5

Tang, X., Bian, S., Tang, M., Lu, Q., Li, S., Liu, X., et al. (2012). MicroRNA-mediated repression of the seed maturation program during vegetative development in Arabidopsis. PLoS Genet. 8:e1003091. doi: 10.1371/journal.pgen.1003091

Tao, Y., Zheng, J., Xu, Z., Zhang, X., Zhang, K., and Wang, G. (2004). Functional analysis of ZmDWF1, a maize homolog of the Arabidopsis 
brassinosteroids biosynthetic DWF1/DIM gene. Plant Sci. 167, 743-751. doi: 10.1016/j.plantsci.2004.05.012

Teale, W. D., Paponov, I. A., and Palme, K. (2006). Auxin in action: signalling, transport and the control of plant growth and development. Nat. Rev. Mol. Cell Biol. 7, 847-859. doi: $10.1038 / \mathrm{nrm} 2020$

Teoh, K. T., Requesens, D. V., Devaiah, S. P., Johnson, D., Huang, X., Howard, J. A., et al. (2013). Transcriptome analysis of embryo maturation in maize. $B M C$ Plant Biol. 13:19. doi: 10.1186/1471-2229-13-19

Tivendale, N. D., Ross, J. J., and Cohen, J. D. (2014). The shifting paradigms of auxin biosynthesis. Trends Plant Sci. 19, 44-51. doi: 10.1016/j.tplants.2013.09.012

Torti, G., Lombardi, L., Manzocchi, L., and Salamini, F. (1984). Indole-3-acetic acid content in viable defective endosperm mutants of maize. Maydica 29, 335-343.

Torti, G., Manzocchi, L., and Salamini, F. (1986). Free and bound indole-acetic acid is low in the endosperm of the maize mutant defective endosperm-B18. Theor. Appl. Genet. 72, 602-605. doi: 10.1007/BF00288997

Ulmasov, T., Hagen, G., and Guilfoyle, T. J. (1999). Activation and repression of transcription by auxin-response factors. Proc. Natl. Acad. Sci. U.S.A. 96, 5844-5849. doi: 10.1073/pnas.96.10.5844

Vanneste, S., and Friml, J. (2009). Auxin: a trigger for change in plant development. Cell 136, 1005-1016. doi: 10.1016/j.cell.2009.03.001

Vanstraelen, M., and Benkova, E. (2012). Hormonal interactions in the regulation of plant development. Annu. Rev. Cell Dev. Biol. 28, 463-487. doi 10.1146/annurev-cellbio-101011-155741

Veach, Y. K., Martin, R. C., Mok, D. W., Malbeck, J., Vankova, R., and Mok, M. C. (2003). O-glucosylation of cis-zeatin in maize. Characterization of genes, enzymes, and endogenous cytokinins. Plant Physiol. 131, 1374-1380. doi: $10.1104 / \mathrm{pp} .017210$

Vert, G., Walcher, C. L., Chory, J., and Nemhauser, J. L. (2008). Integration of auxin and brassinosteroid pathways by Auxin Response Factor 2. Proc. Natl. Acad. Sci. U.S.A. 105, 9829-9834. doi: 10.1073/pnas.0803996105

Vicente-Carbajosa, J., and Carbonero, P. (2005). Seed maturation: developing an intrusive phase to accomplish a quiescent state. Int. J. Dev. Biol. 49, 645-651. doi: $10.1387 / \mathrm{ijdb} .052046 \mathrm{jc}$

Vieten, A., Vanneste, S., Wisniewska, J., Benkova, E., Benjamins, R., Beeckman, T., et al. (2005). Functional redundancy of PIN proteins is accompanied by auxindependent cross-regulation of PIN expression. Development 132, 4521-4531. doi: $10.1242 /$ dev.02027

Vyroubalova, S., Vaclavikova, K., Tureckova, V., Novak, O., Smehilova, M., Hluska, T., et al. (2009). Characterization of new maize genes putatively involved in cytokinin metabolism and their expression during osmotic stress in relation to cytokinin levels. Plant Physiol. 151, 433-447. doi: 10.1104/pp.109.142489

Wabnik, K., Robert, H. S., Smith, R. S., and Friml, J. (2013). Modeling framework for the establishment of the apical-basal embryonic axis in plants. Curr. Biol. 23, 2513-2518. doi: 10.1016/j.cub.2013.10.038

Wang, A., Garcia, D., Zhang, H., Feng, K., Chaudhury, A., Berger, F., et al. (2010a). The VQ motif protein IKU1 regulates endosperm growth and seed size in Arabidopsis. Plant J. 63, 670-679. doi: 10.1111/j.1365-313X.2010.04271.x

Wang, B., Chen, Y., Guo, B., Kabir, M. R., Yao, Y., Peng, H., et al. (2014), Expression and functional analysis of genes encoding cytokinin receptor-like histidine kinase in maize (Zea mays L.). Mol. Genet. Genomics 289, 501-512. doi: 10.1007/s00438-014-0821-9

Wang, H., Nussbaum-Wagler, T., Li, B., Zhao, Q., Vigouroux, Y., Faller, M., et al. (2005). The origin of the naked grains of maize. Nature 436, 714-719. doi: 10.1038/nature 03863

Wang, L., Liu, H., Li, D., and Chen, H. (2011). Identification and characterization of maize microRNAs involved in the very early stage of seed germination. BMC Genomics 12:154. doi: 10.1186/1471-2164-12-154

Wang, Y., Deng, D., Bian, Y., Lv, Y., and Xie, Q. (2010b). Genome-wide analysis of primary auxin-responsive Aux/IAA gene family in maize (Zea mays. L.). Mol. Biol. Rep. 37, 3991-4001. doi: 10.1007/s11033-010-0058-6

Wang, Y., Deng, D., Shi, Y., Miao, N., Bian, Y., and Yin, Z. (2012). Diversification, phylogeny and evolution of auxin response factor (ARF) family: insights gained from analyzing maize ARF genes. Mol. Biol. Rep. 39, 2401-2415. doi: 10.1007/s11033-011-0991-z

Wang, Z. Y., Nakano, T., Gendron, J., He, J., Chen, M., Vafeados, D., et al. (2002). Nuclear-localized BZR1 mediates brassinosteroid-induced growth and feedback suppression of brassinosteroid biosynthesis. Dev. Cell 2, 505-513. doi: 10.1016/S1534-5807(02)00153-3
Waters, A., Creff, A., Goodrich, J., and Ingram, G. (2013a). "What we've got here is failure to communicate": zou mutants and endosperm cell death in seed development. Plant Signal. Behav. 8:e24368. doi: 10.4161/psb.24368

Waters, A. J., Bilinski, P., Eichten, S. R., Vaughn, M. W., Ross-Ibarra, J., Gehring, M., et al. (2013b). Comprehensive analysis of imprinted genes in maize reveals allelic variation for imprinting and limited conservation with other species. Proc. Natl. Acad. Sci. U.S.A. 110, 19639-19644. doi: 10.1073/pnas.1309182110

Waters, A. J., Makarevitch, I., Eichten, S. R., Swanson-Wagner, R. A., Yeh, C. T., Xu, W., et al. (2011). Parent-of-origin effects on gene expression and DNA methylation in the maize endosperm. Plant Cell 23, 4221-4233. doi: $10.1105 /$ tpc. 111.092668

Weber, H., Borisjuk, L., and Wobus, U. (2005). Molecular physiology of legume seed development. Annu. Rev. Plant Biol. 56, 253-279. doi: 10.1146/annurev.arplant.56.032604.144201

Weijers, D., and Jurgens, G. (2005). Auxin and embryo axis formation: the ends in sight? Curr. Opin. Plant Biol. 8, 32-37. doi: 10.1016/j.pbi.2004.11.001

Werner, T., Motyka, V., Laucou, V., Smets, R., Van Onckelen, H., and Schmulling, T. (2003). Cytokinin-deficient transgenic Arabidopsis plants show multiple developmental alterations indicating opposite functions of cytokinins in the regulation of shoot and root meristem activity. Plant Cell 15, 2532-2550. doi: $10.1105 /$ tpc. 014928

West, M., and Harada, J. J. (1993). Embryogenesis in higher plants: an overview. Plant Cell 5, 1361-1369. doi: 10.1105/tpc.5.10.1361

Windels, D., and Vazquez, F. (2011). miR393: integrator of environmental cues in auxin signaling? Plant Signal. Behav. 6, 1672-1675. doi: 10.4161/psb.6.11. 17900

Wojcikowska, B., Jaskola, K., Gasiorek, P., Meus, M., Nowak, K., and Gaj, M. D. (2013). LEAFY COTYLEDON2 (LEC2) promotes embryogenic induction in somatic tissues of Arabidopsis, via YUCCA-mediated auxin biosynthesis. Planta 238, 425-440. doi: 10.1007/s00425-013-1892-2

Wolff, P., Weinhofer, I., Seguin, J., Roszak, P., Beisel, C., Donoghue, M. T., et al. (2011). High-resolution analysis of parent-of-origin allelic expression in the Arabidopsis Endosperm. PLoS Genet. 7:e1002126. doi: 10.1371/journal.pgen. 1002126

Won, C., Shen, X., Mashiguchi, K., Zheng, Z., Dai, X., Cheng, Y., et al. (2011). Conversion of tryptophan to indole-3-acetic acid by TRYPTOPHAN AMINOTRANSFERASES OF ARABIDOPSIS and YUCCAs in Arabidopsis. Proc. Natl. Acad. Sci. U.S.A. 108, 18518-18523. doi: 10.1073/pnas.11084 36108

Wright, A. D., Moehlenkamp, C. A., Perrot, G. H., Neuffer, M. G., and Cone, K. C. (1992). The maize auxotrophic mutant orange pericarp is defective in duplicate genes for tryptophan synthase beta. Plant Cell 4, 711-719. doi: 10.1105/tpc.4.6.711

Wu, G., Park, M. Y., Conway, S. R., Wang, J. W., Weigel, D., and Poethig, R. S. (2009). The sequential action of miR156 and miR172 regulates developmental timing in Arabidopsis. Cell 138, 750-759. doi: 10.1016/j.cell.2009.06.031

Xiao, W., Gehring, M., Choi, Y., Margossian, L., Pu, H., Harada, J. J., et al. (2003). Imprinting of the MEA Polycomb gene is controlled by antagonism between MET1 methyltransferase and DME glycosylase. Dev. Cell 5, 891-901. doi: 10.1016/S1534-5807(03)00361-7

Xin, M., Yang, R., Li, G., Chen, H., Laurie, J., Ma, C., et al. (2013). Dynamic expression of imprinted genes associates with maternally controlled nutrient allocation during maize endosperm development. Plant Cell 25, 3212-3227. doi: $10.1105 /$ tpc. 113.115592

Xing, H., Pudake, R. N., Guo, G., Xing, G., Hu, Z., Zhang, Y., et al. (2011). Genome-wide identification and expression profiling of auxin response factor (ARF) gene family in maize. BMC Genomics 12:178. doi: 10.1186/1471-2164$12-178$

Xing, Q., Creff, A., Waters, A., Tanaka, H., Goodrich, J., and Ingram, G. C. (2013). ZHOUPI controls embryonic cuticle formation via a signalling pathway involving the subtilisin protease ABNORMAL LEAF-SHAPE1 and the receptor kinases GASSHO1 and GASSHO2. Development 140, 770-779. doi: 10.1242/dev. 088898

Yang, S., Johnston, N., Talideh, E., Mitchell, S., Jeffree, C., Goodrich, J., et al. (2008). The endosperm-specific ZHOUPI gene of Arabidopsis thaliana regulates endosperm breakdown and embryonic epidermal development. Development 135, 3501-3509. doi: 10.1242/dev.026708

Yin, Y., Wang, Z. Y., Mora-Garcia, S., Li, J., Yoshida, S., Asami, T., et al. (2002). BES1 accumulates in the nucleus in response to brassinosteroids to 
regulate gene expression and promote stem elongation. Cell 109, 181-191. doi: 10.1016/S0092-8674(02)00721-3

Zhang, B., Pan, X., and Anderson, T. A. (2006). Identification of 188 conserved maize microRNAs and their targets. FEBS Lett. 580, 3753-3762. doi: 10.1016/j.febslet.2006.05.063

Zhang, L., Chia, J. M., Kumari, S., Stein, J. C., Liu, Z., Narechania, A., et al. (2009a). A genome-wide characterization of microRNA genes in maize. PLoS Genet. 5:e1000716. doi: 10.1371/journal.pgen.1000716

Zhang, L. Y., Bai, M. Y., Wu, J., Zhu, J. Y., Wang, H., Zhang, Z., et al. (2009b). Antagonistic HLH/bHLH transcription factors mediate brassinosteroid regulation of cell elongation and plant development in rice and Arabidopsis. Plant Cell 21, 3767-3780. doi: 10.1105/tpc.109.070441

Zhang, M., Xie, S., Dong, X., Zhao, X., Zeng, B., Chen, J., et al. (2014). Genomewide high resolution parental-specific DNA and histone methylation maps uncover patterns of imprinting regulation in maize. Genome Res. 24, 167-176. doi: $10.1101 /$ gr.155879.113

Zhang, M., Zhao, H., Xie, S., Chen, J., Xu, Y., Wang, K., et al. (2011). Extensive, clustered parental imprinting of protein-coding and noncoding RNAs in developing maize endosperm. Proc. Natl. Acad. Sci. U.S.A. 108, 20042-20047. doi: $10.1073 /$ pnas. 1112186108
Zhao, Y., Christensen, S. K., Fankhauser, C., Cashman, J. R., Cohen, J. D., Weigel, D., et al. (2001). A role for flavin monooxygenase-like enzymes in auxin biosynthesis. Science 291, 306-309. doi: 10.1126/science.291.5502.306

Conflict of Interest Statement: The authors declare that the research was conducted in the absence of any commercial or financial relationships that could be construed as a potential conflict of interest.

Received: 27 April 2014; accepted: 03 August 2014; published online: 25 August 2014. Citation: Locascio A, Roig-Villanova I, Bernardi J and Varotto S (2014) Current perspectives on the hormonal control of seed development in Arabidopsis and maize: a focus on auxin. Front. Plant Sci. 5:412. doi: 10.3389/fpls.2014.00412

This article was submitted to Plant Evolution and Development, a section of the journal Frontiers in Plant Science.

Copyright (c) 2014 Locascio, Roig-Villanova, Bernardi and Varotto. This is an openaccess article distributed under the terms of the Creative Commons Attribution License (CC BY). The use, distribution or reproduction in other forums is permitted, provided the original author(s) or licensor are credited and that the original publication in this journal is cited, in accordance with accepted academic practice. No use, distribution or reproduction is permitted which does not comply with these terms. 